\title{
LA REFORMA AL IMPUESTO AL VALOR AgREgAdO dE 1995: EFECTO INFLACIONARIO, INCIDENCIA Y ELASTICIDADES RELATIVAS
}

Fernando Aportela Rodríguez

Alejandro Werner Wainfeld

Enero, 2002

Documento de Investigación No. 2002-01

Dirección General de Investigación Económica

BANCO DE MÉXICO 


\title{
LA ReForma AL IMPUeSto AL VALOR AgREgado de 1995: EFECTO INFLACIONARIO, INCIDENCIA Y ELASTICIDADES ReLATiVAS
}

\author{
Fernando Aportela y Alejandro Werner*
}

Enero, 2002

Documento de Investigación No. 2002-01

\begin{abstract}
Resumen
El primero de abril de 1995, el gobierno mexicano incrementó la tasa del impuesto al valor agregado de 10 a 15 por ciento en las ciudades del interior del país, mientras que en las poblaciones fronterizas se mantuvo en 10 por ciento. Esta medida de política es utilizada en este artículo como un experimento natural que brinda la oportunidad de estudiar tres cosas: los efectos inflacionarios, la incidencia del IVA y la elasticidad relativa de la demanda de los bienes y servicios de la economía. En este trabajo se utilizan datos mensuales de los precios de los 313 productos genéricos que conforman el INPC en 46 ciudades fronterizas y no fronterizas entre febrero y diciembre de 1995. El comportamiento de los precios en las poblaciones fronterizas se utiliza como variable de control para identificar los efectos que tuvo el cambio en el IVA sobre los precios en las ciudades no fronterizas. Los resultados obtenidos indican que el efecto inflacionario de la reforma fiscal desapareció tras dos meses de haber sido implantada. La incidencia impositiva estimada y el valor de las elasticidades relativas son acordes a lo indicado por la teoría económica. Aquellos grupos de productos como alimentos, bebidas y tabaco; cuidados personales y; cuidados de la salud presentan una incidencia más alta y una demanda relativamente más inelástica que su oferta. Por otro lado, bienes y servicios como los artículos de cristalería, blancos y utensilios domésticos; artículos de esparcimiento ; enseres domésticos y mantenimiento de la vivienda mostraron una incidencia menor y una demanda relativamente menos elástica que la oferta. Los resultados encontrados son útiles para el diseño de la política, para la evaluación de sus efectos fiscales sobre la distribución del ingreso y para la reacción adecuada de la política monetaria ante cambios en impuestos indirectos.
\end{abstract}

\footnotetext{
* Ambos autores prestan sus servicios en la Dirección de Estudios Económicos del Banco de México y agradecen la ayuda de Eduardo Espinosa y Roberto Durán en la elaboración de este trabajo. Las opiniones corresponden exclusivamente a los autores y no representan las del Banco de México. Contactos: Fernando Aportela, 5237-2561, faporte@banxico.org.mx. Alejandro Werner, 5237-2573, awerner@banxico.org.mx. Dirección: 5 de Mayo \#18. $4^{\circ}$ Piso. Colonia Centro. CP 06059. México, D.F.
} 


\section{Introducción}

Dos de los principales elementos que deben considerarse en el diseño y evaluación de un impuesto indirecto son sus efectos sobre la eficiencia económica y la distribución del ingreso. Sin embargo, dada la información disponible la mayoría de las veces es difícil evaluar estos efectos. En principio, es necesario contar para cada uno de los bienes gravados con una estimación de las elasticidades de la demanda y de la oferta así como de los precios que enfrentan consumidores y productores. La falta de estudios sobre este tema se debe probablemente a la gran cantidad de información que requieren y a la dificultad para estimar algunos de los parámetros mencionados. ${ }^{1}$

En la actualidad, el análisis de estos efectos es de un interés particular para México y para muchos países de América Latina. Recientemente, el gobierno mexicano envió al Congreso una propuesta de reforma al IVA, que incluye la reducción de las exenciones a dicho impuesto, la eliminación de la tasa cero y la homologación a una tasa única. Un aspecto clave para la evaluación de esta reforma es el estudio de su impacto sobre la distribución del ingreso y las implicaciones en términos de eficiencia. ${ }^{2}$ En muchos países de América Latina, tal como lo expuso Shome (1999), la productividad del IVA (definida como la recaudación del impuesto expresada como porcentaje del PIB dividida entre la tasa impositiva) es baja. Esto refleja la erosión existente de la base tributaria debido principalmente a las exenciones fiscales, la evasión y los vacíos administrativos. Dado el inconveniente de incrementar los ingresos tributarios a través de mayores impuestos al capital (debido a su movilidad internacional y en el mediano plazo a sus efectos sobre la productividad del mismo), los sistemas de impuestos indirectos de muchos países de la región, requerirán en el futuro próximo de importantes reformas.

\footnotetext{
${ }^{1}$ Ahmand y Stern (1984) han analizado la eficiencia de los impuestos indirectos en la India y proponen reformas que incrementan el bienestar.

${ }^{2}$ Levy (2000) discute el efecto de la reforma del IVA sobre el ingreso y presenta estrategias para eliminar su efecto negativo en la población de menores ingresos. Sin embargo, debido a la falta de información, el autor tiene que inferir el impacto inflacionario de la política fiscal en los precios de los bienes y servicios de la economía.
} 
El $1^{\text {o }}$ de abril de 1995, como parte del programa de ajuste macroeconómico entonces instrumentado para superar la crisis económica, el gobierno mexicano aumentó la tasa del Impuesto al Valor Agregado (IVA) de 10 a 15 por ciento en todo el país con excepción de las ciudades fronterizas. En esas ciudades, se mantuvo la tasa en 10 por ciento. Esta medida de política constituye un experimento natural único que brinda la oportunidad para estudiar tres cuestiones: los efectos inflacionarios, la incidencia del impuesto al valor agregado y la elasticidad relativa entre la demanda y la oferta de los bienes y servicios en la economía. Existen elementos que validan el uso de la reforma de 1995 como un experimento natural. ${ }^{3}$ La reforma impositiva se realizó con el propósito de fortalecer la postura fiscal del gobierno federal. Claramente, ésta no tenía como fin afectar a los precios, ni perseguía objetivos distributivos.

En este artículo se utilizan los datos mensuales de los precios de los 313 productos genéricos que integran el Índice Nacional de Precios al Consumidor (INPC) en 46 ciudades fronterizas y no fronterizas, entre febrero y diciembre de 1995. La información se agrupa en 14 categorías de gasto y se utiliza para el análisis el IPC de cada una de esas ciudades. Los resultados de esta investigación indican que la magnitud del impacto inflacionario total de la reforma del IVA de 1995 fue aproximadamente de 2.25 puntos porcentuales. Asimismo, este efecto tuvo lugar durante los primeros dos meses que siguieron a la aplicación de la reforma y no fue significativo después de dicho periodo.

Los resultados muestran una mayor incidencia del impuesto sobre los consumidores en bienes y servicios tales como: alimentos, bebidas, tabaco y cuidados personales. La incidencia al consumidor resultó mucho menor para productos tales como artículos de cristalería, blancos, utensilios domésticos; y artículos de esparcimiento.

\footnotetext{
${ }^{3}$ Como se mostrará más adelante, el resultado del experimento desfasado confirma la validez de la reforma del IVA de 1995 como un experimento natural.
} 
Los resultados referentes a las elasticidades relativas entre la demanda y la oferta, indican que en el caso de bienes como educación y cultura; artículos de cristalería, blancos y utensilios domésticos; la elasticidad de la oferta es relativamente menor que la de la demanda.

El resto del documento se organizó de la siguiente manera: en la sección II se describe la estructura del IVA y la reforma a este impuesto que tuvo lugar en 1995. En dicha sección también se discute si este cambio de política puede considerarse como un experimento natural y se presentan los datos utilizados en el trabajo. En la sección III se incluye la estrategia empírica y los principales resultados de la investigación. Además, se presenta una estimación del efecto inflacionario de la reforma impositiva aludida; de la incidencia del impuesto y de los resultados sobre la elasticidad relativa de la demanda y de la oferta. Finalmente, en la sección IV se discuten las principales conclusiones.

\section{El Cambio Impositivo}

\subsection{La reforma del IVA de 1995}

Desde su introducción en México en 1980, el IVA ha experimentado 5 reformas. A excepción del periodo de 1992 a 1994 (cuando únicamente existían dos tasas impositivas), la estructura del IVA siempre ha mostrado más de dos tasas. En general, la estructura impositiva de ese gravamen ha sido la siguiente: bienes exentos, tasa cero, tasa de ciudades fronterizas y tasa general. ${ }^{4}$

Desde su introducción, ha habido varios bienes y servicios cuyo consumo ha quedado exento del IVA. Entre estos bienes se incluyen libros y revistas, educación, algunos servicios médicos, servicios de esparcimiento y transportación no ferroviaria. Asimismo, muchos bienes han sido y están gravados a una tasa cero. Entre éstos encontramos los

\footnotetext{
${ }^{4}$ Para un análisis más detallado sobre la estructura del IVA en México véase Casanegra, et. al. (1995), OECD (1999) y SHCP (2001).
} 
siguientes: alimentos, medicinas, compra de terrenos, maquinaria agrícola y construcción de vivienda. ${ }^{5}$

Durante la mayor parte del tiempo, en la región fronteriza el IVA ha tenido una tasa impositiva especial. Esta región se encuentra dentro de una franja de veinte kilómetros a partir de las fronteras norte y sur del país. En dicha zona, con esta tasa impositiva se grava a todos los bienes y servicios que no caen en la categoría de exentos o tasa cero. La tasa general del IVA aplicable en el resto del país se carga a los mismos bienes y servicios que la tasa de la zona fronteriza. No obstante, la tasa general casi siempre ha sido más alta que la aplicada en las zonas fronterizas. ${ }^{6}$

Después de la devaluación del peso de diciembre de 1994 y de la crisis económica que le siguió, el gobierno federal introdujo medidas de austeridad y un programa de emergencia para superarla. Uno de los principales pilares de esta estrategia fue el fortalecimiento de las finanzas públicas, donde la reforma del IVA fue parte central de este esfuerzo.

Esta reforma consistió en aumentar la tasa general del IVA de 10 a 15 por ciento el $1^{\circ}$ abril de 1995. El número de bienes y servicios exentos y con tasa cero permaneció sin cambio, al igual que la tasa impositiva en las zonas fronterizas.

\subsection{La Reforma del IVA como un Experimento Natural y Descripción de los Datos}

La reforma del IVA de 1995 constituye un experimento natural único. Dado que la tasa del IVA se incrementó únicamente en las regiones no fronterizas del país, el comportamiento de los precios en las zonas fronterizas puede ser utilizado como variable de control para estudiar los efectos de este cambio de política. Por tanto, es posible comparar antes y después de que el incremento de la tasa impositiva fuese aplicado la inflación de los bienes

\footnotetext{
${ }^{5}$ La diferencia entre los bienes y servicios exentos y los gravados a tasa cero radica en el tratamiento que se da a la deducción del IVA. Bajo el régimen de tasa cero, los productores pueden deducir el IVA pagado en etapas anteriores de producción. Por el contrario, si los bienes y servicios son exentos de IVA, esta deducción no es posible.

${ }^{6}$ La única excepción se presentó en el periodo que va de 1992 a 1994, cuando la tasa general del IVA fue igual que la tasa de la zona fronteriza.
} 
y servicios en las zonas del país afectadas por la reforma, con la que tuvo lugar en la región fronteriza.

La reforma del IVA califica como un experimento natural en la medida en que dicho cambio de política no fue endógeno al comportamiento de los precios y no respondió a ningún objetivo distributivo. La reforma del IVA se realizó con el propósito de fortalecer las finanzas públicas, por lo que la acción del gobierno no respondía a los factores antes mencionados. La reforma buscaba garantizar la solvencia del gobierno federal dada la escasez de recursos públicos y el elevado costo de refinanciamiento de la deuda pública.

Un aspecto importante para la validez de un experimento natural es el grado de similitud entre los grupos de control y experimental. En este caso, el grupo experimental quedó integrado por los precios de los bienes y servicios de las zonas no fronterizas, mientras que los precios de los mismos bienes en las regiones fronterizas conformaron el grupo de control. Es posible argumentar que la sensibilidad de la demanda por bienes comerciables es mayor en las poblaciones fronterizas debido a su proximidad con el mercado extranjero. Sin embargo, en la medida en que la sensibilidad no cambió durante el periodo de estudio, la estrategia empírica utilizada en este artículo permitió eliminar el problema.

Tradicionalmente, una manera de medir el grado de similitud entre el grupo de control y el experimental es a través de un experimento desfasado. Este ejercicio consiste en replicar los cálculos del experimento original pero durante un período en el que no haya tenido lugar ningún cambio de política. Como se muestra más adelante, este ejercicio se realizó para el INPC y para cada precio analizado. Los resultados indican un alto grado de similitud entre los dos grupos. 


\section{Descripción de los Datos}

En este documento se utilizan los índices de precios de 313 bienes y servicios genéricos en 46 ciudades de México; de las cuales 38 no se encuentran en la región fronteriza. ${ }^{7}$ Por tanto, se cuenta con un índice de precios para cada uno de los genéricos enunciados en cada una de estas ciudades. Estos 313 bienes y servicios integran la canasta del INPC. La periodicidad de los datos es mensual y comprende de febrero a diciembre de 1995. Utilizando el índice de precios de cada producto se calculó la respectiva inflación mensual. De tal forma, se cuenta con información sobre los precios y la trayectoria inflacionaria para cada bien, tanto para las poblaciones fronterizas como para las no fronterizas. Con base en ello fue posible construir grupos de control y experimental basados en la ubicación en la cual los bienes fueron comercializados.

En un esfuerzo por sintetizar y ordenar la información, los bienes y servicios de la muestra se agruparon en categorías diferentes de gasto. Estas categorías son las mismas que se utilizan en la Encuesta Nacional de Ingreso Gasto de los Hogares en México. ${ }^{8}$ Estas son: alimentos, bebidas y tabaco; transporte público; limpieza y cuidado de la casa; cuidados personales; educación, cultura y recreación; comunicaciones y servicios para vehículos; vivienda, servicios de conservación y electricidad; prendas de vestir, calzado y accesorios; cristalería, blancos y utensilios domésticos; cuidados de la salud; enseres domésticos y mantenimiento de la vivienda; artículos de esparcimiento; transporte; y otros gastos. En el Cuadro 1 se presenta el número de productos en cada categoría, el número de los que están exentos del IVA, que pagan tasa cero y gravados con la tasa general.

Se calculó también la inflación mensual para cada ciudad, utilizando el IPC de la localidad correspondiente. En el Cuadro 2 se presenta la inflación mensual promedio observada en las poblaciones fronterizas y no fronterizas, antes y después de la reforma del IVA. Ahí puede apreciarse que la inflación promedio mensual para las poblaciones fronterizas y no fronterizas fue similar antes de la reforma: 5.7 y 5.5 por ciento respectivamente. La

\footnotetext{
${ }^{7}$ En el Apéndice 1 se presenta la lista de las ciudades consideradas para la elaboración de este documento. La información sobre los precios de los bienes y servicios de estas ciudades es recolectada mensualmente por el Banco de México.
} 
diferencia entre los niveles de inflación promedio correspondientes a los dos tipos de localidades no resultó significativa estadísticamente. Sin embargo, en abril y mayo de 1995 la inflación mensual promedio en las ciudades no fronterizas fue mayor y esta diferencia sí resultó significativa estadísticamente.

\section{Estrategia Empírica y Principales Resultados}

La reforma del IVA aplicada en 1995 brinda una oportunidad única para estudiar los efectos que causan sobre los precios los impuestos indirectos, así como la incidencia del impuesto al valor agregado y las elasticidades relativas de los bienes y servicios en la economía. Esto, dado que a raíz de la reforma, los mismos productos fueron gravados con diferente tasa dependiendo del lugar en que éstos fueran comercializados. Por ejemplo, en marzo de 1995 una bicicleta pagaba un IVA de 10\% de su valor independientemente de la ciudad en que fuera adquirida. Sin embargo en abril de 1995, la misma bicicleta pagaba una tasa de $10 \%$ si esta se comercializaba en Tijuana (ciudad dentro de la región fronteriza) o $15 \%$ si era vendida en la Ciudad de México. Por tanto, es posible comparar el comportamiento del precio de este producto en Tijuana contra el observado en la Ciudad de México.

Utilizando información sobre los precios en 46 ciudades de la muestra se creó un grupo experimental y otro de control. El grupo de control se formó con los precios de bienes y servicios comercializados en las poblaciones fronterizas de febrero a diciembre de 1995. Por otro lado, en el grupo experimental se incluyó información sobre los precios de dichos bienes y servicios durante el mismo periodo, pero comercializados en las poblaciones fuera de la zona fronteriza.

La estrategia empírica consistió en lo siguiente: (a) se construyó una variable dummy para los bienes y servicios comercializados en las poblaciones fuera de la región fronteriza (la variable toma un valor de 1 si el bien fue vendido en una ciudad del interior del país); (b) se

\footnotetext{
${ }^{8}$ INEGI (1994).
} 
construyó una variable dummy para los meses posteriores a la fecha en que se llevó a cabo la reforma (esta variable toma un valor de 1 durante el periodo que va de abril a diciembre de 1995); (c) se calculó la interacción entre estas dos variables dummy (la cual permitió identificar a las ciudades del interior del país durante el periodo de abril a diciembre de 1995).

Mediante el método de Mínimos Cuadrados Ordinarios, se estimó la siguiente ecuación para la inflación mensual:

$$
\begin{aligned}
& \pi_{i, m}=\beta_{0}+\beta_{l} \times \text { Dummy_No_Fronteriza } a_{i}+\beta_{2} \times \text { Dummy_Después_Reforma }_{m} \\
& +\beta_{3} \times\left(\text { Dummy_No_Fronteriza } a_{i} \times \text { Dummy_Después_Reforma } m\right)+\varepsilon_{i, m}
\end{aligned}
$$

donde $i$ denota el tipo de bien, servicio, categoría de gasto o INPC y $m$ el mes de la observación. Vale la pena señalar que la ecuación (1) se estimó de forma individual para los meses de abril a diciembre de 1995. Cada una de estas ecuaciones se estimó con información del mes de marzo y de cada uno de los meses siguientes a la reforma del IVA. Por tanto, se estimaron 9 ecuaciones para cada bien, servicio, categoría de gasto e INPC.

La ecuación (1) es la representación matemática del enfoque de "diferencias en diferencias" utilizado comúnmente en la literatura de los experimentos naturales. La ventaja de esta metodología reside en que cualquier diferencia entre el grupo de control y experimental que no dependa del periodo (es decir, fija en el tiempo) es eliminada por la doble diferencia. Esto se logra gracias a las dummies de localización y de periodo. Además, este método controla por cualquier tendencia en los datos. Lo anterior era crucial para fines de poder identificar los efectos de la reforma del IVA, ya que en los primeros meses de 1995 la inflación experimentó un repunte en sus niveles a lo cual le siguió un decremento significativo.

Así, la interacción del coeficiente de las variables Dummy_No_Fronteriza y Dummy_Después_Reforma $\left(\beta_{3}\right)$ permitió capturar el impacto inflacionario de la reforma 
del IVA. En el caso del INPC este coeficiente resulta una indicación de cuantos puntos porcentuales aumentó el índice de precios agregado como consecuencia del incremento en la tasa del impuesto. Por otro lado mediante la estimación de esta ecuación para todos los meses posteriores a la reforma, fue posible determinar el efecto total sobre los precios derivado del cambio de política, así como el mes en el cual el efecto inflacionario dejó de ser estadísticamente significativo.

\subsection{Efectos Inflacionarios}

En esta sección se presentan los resultados de la estimación del efecto inflacionario atribuible a la reforma del IVA. Primero se muestran los resultados para el INPC, seguidos de los correspondientes a cada categoría de gasto. Como parte del análisis se realizaron cálculos similares para cada bien y servicio gravado con la tasa general de IVA. Estos resultados se encuentran en un apéndice al final del documento.

\subsubsection{Resultados del Índice de Precios al Consumidor}

Los principales resultados de esta sección se muestran en el Cuadro 3. En su segunda columna se presenta el experimento desfasado. Este consistió en estimar la ecuación (1) utilizando la inflación mensual de febrero y marzo de 1995. Por tanto, esta regresión cubre un periodo previo al de la reforma del IVA. El resultado de este ejercicio muestra que en las ciudades no fronterizas la inflación fue en el lapso 0.79 puntos porcentuales menor que en las comunidades fronterizas (este coeficiente resultó estadísticamente significativo). El resultado referido se explica principalmente por los efectos inmediatos causados por la devaluación del peso en las ciudades fronterizas. ${ }^{9}$

En el ejercicio para el experimento desfasado, la variable Dummy_Después_Reforma es en realidad una variable dummy para el mes de marzo. Su coeficiente tomó un valor de 0.83

\footnotetext{
${ }^{9}$ La velocidad de transmisión del tipo de cambio sobre los precios presumiblemente es mayor en las regiones fronterizas del país. Sin embargo, el crecimiento de los precios en el interior del país cierra la brecha relativamente rápido. De hecho, el coeficiente negativo de las comunidades no fronterizas no es estadísticamente significativo en todos los meses restantes de 1995.
} 
puntos porcentuales y resultó altamente significativo. Esto se debe principalmente a la aceleración que experimentó la inflación a principios de 1995.

Finalmente, el coeficiente del efecto inflacionario de la reforma (es decir, el coeficiente de la interacción de las dos variables dummy) tomó un valor de 0.53 puntos porcentuales y no resultó estadísticamente significativo. Los resultados del experimento desfasado aportan evidencia de que el grupo de control es adecuado para realizar una comparación. Esto es porque en ausencia de un cambio de política, el coeficiente de "diferencias en diferencias" no es significativo, indicando que las características inflacionarias de los grupos de control y experimental son similares.

Los resultados del ejercicio de experimento natural indican un impacto importante sobre la inflación mensual del INPC a consecuencia del cambio de política. Según la estimación de la ecuación (1) para el periodo de marzo a abril, el efecto inflacionario de la reforma del IVA ascendió a 1.53 puntos porcentuales y resultó altamente significativo. Esto implica que la inflación de los precios al consumidor en abril fue 1.53 puntos mayor debido al incremento de la tasa del IVA. En el caso de la variable dummy para ciudades no fronterizas, el coeficiente tomó un valor de -0.26 puntos porcentuales y no fue significativo. El valor del coeficiente estimado para la variable Dummy_Después_Reforma resultó de 0.88 puntos porcentuales y no fue significativo estadísticamente.

En la estimación para el periodo de marzo a mayo, el valor del coeficiente de interacción de las variables Dummy_No_Fronteriza y Dummy_Después_Reforma resultó de 0.72 puntos porcentuales y fue significativo estadísticamente. El coeficiente de la variable dummy para las ciudades no fronterizas no fue estadísticamente significativo, mientras que el coeficiente de la variable dummy para después de la reforma tomó un valor de -2.13 y fue altamente significativo (lo anterior es atribuible a un efecto estacional y a la desaceleración de la inflación).

En la Gráfica 1 se presenta el efecto inflacionario mensual de la reforma del IVA en el periodo de marzo a diciembre de 1995 (el efecto inflacionario de marzo fue estimado por el 
coeficiente de interacción del experimento desfasado). ${ }^{10}$ Ahí también se muestra el intervalo de confianza del 95 por ciento de los coeficientes estimados. En la gráfica se aprecia que el impacto del incremento del IVA sólo resultó significativo durante los dos meses siguientes a su entrada en vigor (el coeficiente de junio es estadísticamente significativo a un nivel del 13 por ciento). Asimismo, es claro que el efecto tendió a desaparecer con el tiempo. Este resultado implica que la inflación que se derivó de la modificación de las tasas del IVA sobre el INPC ascendió a 2.25 puntos porcentuales.

\subsubsection{Resultados por Categoría de Gasto}

El segundo ejercicio consistió en estimar la ecuación (1) para cada categoría de gasto. Dicha estimación respondió a la finalidad de evaluar para cada una de ellas, el efecto inflacionario mensual de la reforma del IVA de abril a diciembre de 1995. Asimismo también, se realizó el experimento desfasado para cada categoría de gasto. A fin de hacer posibles estos cálculos, la muestra de bienes y servicios se restringió a aquellos gravados con la tasa general del IVA, por lo que las categorías de gasto solo incluyen en total 170 bienes y servicios.

En el Cuadro 4 se recoge únicamente el efecto inflacionario mensual (es decir, el coeficiente de interacción entre las variables dummy para los meses después de la reforma y para las ciudades no fronterizas). Puede apreciarse en dicho cuadro que la mayoría de los coeficientes de interacción no resultaron estadísticamente significativos en el experimento desfasado. Únicamente los impactos inflacionarios en lo rubros de educación, cultura y recreación; y prendas de vestir calzado y accesorios, resultaron significativos estadísticamente a un nivel de 10 por ciento.

De acuerdo con los resultados obtenidos para las categorías de gasto, en abril de 1995 el efecto inflacionario mensual de la reforma del IVA fue relevante para la mayoría de éstas.

\footnotetext{
${ }^{10}$ Esta gráfica se construyó estimando la Ecuación (1) para cada mes del periodo de análisis. De junio a diciembre los coeficientes estimados para la variable dummy de ciudad no fronteriza, no fueron estadísticamente significativos y para la variable dummy para después de la reforma resultó negativo y significativo, como consecuencia lógica de la desaceleración de la inflación.
} 
El coeficiente de interacción entre las variables dummy para dicho mes y para los meses posteriores a la reforma y para ciudades no fronterizas tuvo un valor superior a 2 puntos porcentuales y fue estadísticamente significativo en las siguientes categorías: alimentos, bebidas y tabaco; vivienda, servicios de conservación y electricidad; prendas de vestir calzado y accesorios; cristalería blancos y utensilios domésticos; cuidados de la salud; enseres domésticos y mantenimiento de la vivienda; y transporte.

Asimismo, las siguientes categorías de gasto no mostraron en abril de 1995 un impacto inflacionario significativo a causa de la reforma del IVA: transporte público; comunicaciones y servicios para vehículos; artículos de esparcimiento; y otros gastos.

En el caso del transporte público, comunicaciones y servicios para vehículos y otros gastos, el resultado se dio conforme a lo esperado. Ello toda vez que los precios de muchos de estos bienes y servicios eran administrados o concertados por la autoridad. ${ }^{11}$ En el caso de los artículos de esparcimiento, el coeficiente del efecto inflacionario resultó de 2.1 puntos porcentuales y sólo fue estadísticamente significativo a un nivel de confianza del 15 por ciento. Esta categoría de gasto incluye a los aparatos electrodomésticos (como televisores, video-caseteras y aparatos de sonido), juguetes, equipo fotográfico, entre otros.

Resulta importante mencionar que para la mayoría de las categorías de gasto, el efecto inflacionario de la reforma del IVA no resulta estadísticamente significativo en mayo o en los meses subsecuentes a la reforma. El mayor impacto sobre los precios originado por el cambio de política económica se concentró en el mes en que entró en vigor la reforma.

\subsection{Incidencia del Impuesto}

La incidencia de un impuesto es cuestión clave en el diseño de cualquier sistema impositivo, así como para la evaluación de sus efectos distributivos. En esta sección se presentan estimaciones sobre la incidencia impositiva de la reforma del IVA para cada

${ }^{11}$ Los bienes y servicios incluidos en esta categoría de gasto son: taxi, metro, transporte urbano, telefonía local, larga distancia nacional e internacional, gasolina, cuotas por licencias de manejo y derechos de tenencia de vehículos automotores, entre otros. 
categoría de gasto. ${ }^{12}$ Consecuentemente, se realizaron cálculos sobre el cambio en los precios del productor y consumidor ocasionados por el incremento de la tasa del IVA del 10 al 15 por ciento.

Sea $q_{c, i}$ el precio del bien $i$ pagado por el consumidor y $P_{c, i}$ el precio del bien $i$ recibido por el productor de los bienes comercializados en una ciudad fronteriza. Entonces, la relación entre estos precios se puede describir con la siguiente ecuación:

$$
q_{c, i}=P_{c, i} \times\left(1+\tau_{0}\right)
$$

Donde $\tau_{0}$ es la tasa del IVA en la región fronteriza. Utilizando el efecto inflacionario estimado del cambio de política sobre el bien $i$ se puede calcular un precio al consumidor ajustado para cada bien comercializado en la zona fronteriza. La siguiente expresión muestra el precio ajustado:

$$
q_{c, i, A}=q_{c, i} \times\left(1+\text { Efecto__nflacionario }_{i}\right)
$$

Por tanto, el precio del productor ajustado por el efecto inflacionario para el bien $i \mathrm{y}$ comercializado en la región fronteriza es el siguiente:

$$
P_{c, i, A}=q_{c, i, A} /\left(1+\tau_{1}\right)
$$

Donde $\tau_{1}$ es la tasa general del IVA después de la reforma. Así, para calcular la incidencia del impuesto primero debe estimarse el cambio en los precios del consumidor y del productor, antes y después de la reforma. Los cambios absolutos para cada tipo de precio se definen de la siguiente manera:

\footnotetext{
${ }^{12}$ Tal como se hizo en la sección anterior, los bienes y servicios considerados son únicamente aquéllos que pagan la tasa general del IVA.
} 


$$
\begin{aligned}
& \text { Cambio_en_el_precio_del_consumidor }=q_{c, i, A}-q_{c, i} \\
& \text { Cambio_en_el_precio_del_Productor }=P_{c, i, A}-P_{c, i}
\end{aligned}
$$

El valor del cambio del precio al consumidor menos el valor del cambio del precio al productor representa el cambio total en precios ocasionado por la reforma del IVA. Suponiendo que existe una relación lineal entre el cambio en los precios y la tasa general del IVA, la incidencia puede expresarse como el cambio en el precio de un bien dividido por el cambio total de los precios. Sea $j=\{$ consumidor, productor $\}$, entonces la incidencia impositiva puede definirse de la siguiente forma:

$$
\text { Incidencia_precio }{ }_{j}=\frac{\text { Cambio_precio }{ }_{j}}{\left(q_{c, i, A}-q_{c, i}\right)-\left(P_{c, i, A}-P_{c, i}\right)}
$$

La incidencia del impuesto se calculó para cada categoría de gasto. ${ }^{13} \mathrm{El}$ efecto inflacionario utilizado para realizar esta estimación para cada uno de ellos fue el de abril de 1995 (Cuadro 4). Esta decisión se tomó debido a que únicamente el efecto inflacionario de ese mes resultó significativo para la mayoría de las categorías. Sin embargo, hay algunas para las cuales se obtuvieron coeficientes significativos estadísticamente en otros meses; aunque algunos de estos resultados pudieran relacionarse con efectos estacionales (por ejemplo, la reducción de la tarifa eléctrica durante el verano en las regiones fronterizas) o bien pudieron deberse a cambios en los precios administrados.

En el Cuadro 5 se muestran los resultados obtenidos en cuanto a la estimación de la incidencia del cambio impositivo aquí estudiado. Como se aprecia, la incidencia sobre el consumidor resultó considerablemente mayor que sobre los productores en las siguientes categorías de gasto: alimentos, bebidas y tabaco; limpieza y cuidados de la casa; cuidados personales; vivienda, servicios de conservación y electricidad; prendas de vestir calzado y accesorios; cuidados de la salud y; transporte. De acuerdo con estos resultados, los

\footnotetext{
${ }^{13}$ En el Apéndice 3, al final del documento, se muestra la incidencia del impuesto calculada para cada producto en lo particular.
} 
productores pagaron el total del incremento al impuesto en el caso de los artículos de esparcimiento (como se mencionó anteriormente, la categoría otros gastos incluye muchos bienes y servicios con precios administrados). Finalmente, en el caso de las categorías educación, cultura y recreación y; cristalería blancos y enseres domésticos, el incremento a la tasa del IVA tuvo una incidencia ligeramente mayor sobre los productores que respecto a los consumidores.

\subsection{Elasticidades Relativas}

Dadas las incidencias estimadas para los precios al consumidor y al productor ante la reforma del IVA, es posible calcular una medida para la elasticidad relativa de la demanda y de la oferta de cada bien y servicio. La condición de equilibrio en cualquier mercado está dada por la siguiente expresión:

$$
S(P)=D(P+t)
$$

donde $S$ representa la oferta del bien, $D$ la demanda del bien y $t$ el impuesto por unidad. Diferenciando y reordenando la ecuación (7) se obtiene:

$$
d P=\frac{\eta_{D}}{\eta_{s} \times \frac{P+t}{P}-\eta_{D}} \times d t
$$

Donde $\eta_{D}$ y $\eta_{s}$ representan las elasticidades de la demanda y de la oferta respectivamente. ${ }^{14}$ Resolviendo la ecuación (8) para el cociente de elasticidades se obtiene la siguiente expresión:

$$
\frac{\eta_{D}}{\eta_{s}}=\frac{(P+t)}{(d t+d P) \times P} \equiv \boldsymbol{\theta}
$$

\footnotetext{
${ }^{14}$ Se supone que ambas elasticidades presentan los signos usuales.
} 
Por tanto, el cociente de las elasticidades es igual al precio del productor más el impuesto por unidad (es decir, el precio que paga el consumidor) dividido por el precio que cobra el productor multiplicado por el cambio en el impuesto más el cambio en el precio del productor. Una $\theta$ alta implica una demanda relativamente más elástica que la oferta lo cual se traduce lógicamente en una menor incidencia del impuesto sobre los consumidores.

Mediante el precio de los bienes y servicios comercializados en las poblaciones fronterizas antes del cambio de política y la estimación del efecto inflacionario de la reforma del IVA, se calculó el parámetro $\boldsymbol{\theta}$ para cada categoría de gasto. ${ }^{15}$ Estos resultados se presentan en el Cuadro 6. Como puede apreciarse, la categoría de gasto de cuidados de la salud, arrojó la menor elasticidad relativa (el cociente estimado es de 0.22). Esto implica que la elasticidad relativa de la demanda es pequeña al compararla con la elasticidad de la oferta. La mayor elasticidad relativa correspondió a la categoría de gasto de cristalería blancos y utensilios domésticos con un valor del parámetro $\theta$ igual a 0.48 . Finalmente, en el caso de los artículos de esparcimiento la oferta resultó mucho más inelástica que la demanda, lo que se tradujo en una imposibilidad para calcular el parámetro $\theta$ para esta categoría.

${ }^{15}$ El efecto inflacionario se define tal como se hizo en la sección anterior: sólo se consideraron los coeficientes que resultaron estadísticamente significativos de las variables de interacción en abril. En el Apéndice 4 se muestran los cálculos que estiman el parámetro $\boldsymbol{\theta}$ para los 170 bienes y servicios que pagan la tasa general del IVA. 


\section{Conclusiones}

En este trabajo se utilizó la reforma del IVA de 1995 como un experimento natural para estudiar el impacto inflacionario de un cambio en la tasa de dicho impuesto. De acuerdo con los resultados obtenidos, el aumento de la tasa impositiva del IVA en 1995 incrementó la inflación en 2.25 puntos porcentuales durante un periodo de dos meses. El efecto de la reforma resultó insignificante a partir del segundo mes posterior a la entrada en vigor de la reforma.

Los ejercicios realizados tanto para estimar la incidencia del impuesto como la elasticidad relativa de la demanda y de la oferta arrojaron resultados acordes a lo esperado con la teoría económica. Los bienes y servicios básicos mostraron una menor elasticidad de demanda, mientras que los productos de entretenimiento y otros bienes no básicos presentaron, en general, una mayor elasticidad de demanda.

Los resultados contenidos en este documento son muy relevantes para la evaluación de los efectos distributivos que puede tener una reforma del sistema impositivo, así como para guiar la aplicación de la política monetaria en respuesta a perturbaciones inflacionarias ocasionados por cambios en los impuestos indirectos. Estos resultados son por tanto de interés para México, Latinoamérica y otros países en vías de desarrollo que estén considerando introducir reformas en la estructura de sus sistemas impositivos. 


\section{Referencias}

[1] Ahmad, Ehtisham, and N. Stern. "The Theory of Reform and Indian Indirect Taxes". Journal of Public Economics, 25, 1984.

[2] Casanegra, M., A. Pellechio, J. Escolano, and P. Bernd, "Mexico: Strengthening the Fiscal System for Growth and Stability". IMF, Fiscal Affairs Department, September 1995.

[3] Inegi, Encuesta Nacional de Ingresos y Gastos de los Hogares. Documento Metodológico. 1994.

[4] Levy, Santiago. "Impacto Redustributivo y Posibles Estrategias para la Compensación de un Cambio en el IVA". SHCP, October, 2000.

[5] OECD, Economic Surveys: México, Chapter III, 1999.

[6] Shome, Pathasarathi. "Taxation in Latin America: Structural Trends and Impact of Administration". IMF Working Paper, WP/99/19, February, 1999. 


\section{Cuadro 1}

\section{Número de Bienes y Servicios en Cada Categoría de Gasto y en Cada Tratamiento de IVA}

\begin{tabular}{lcccr}
\hline \hline Categoría & Total & Exentos & Cero & Tasa General \\
\hline \hline & 139 & 0 & 125 & 14 \\
Alimentos, Bebidas y Tabaco & 5 & 0 & 0 & 5 \\
Transporte Público & 12 & 0 & 0 & 12 \\
Limpieza y Cuidado de la casa & 15 & 0 & 0 & 15 \\
Cuidados Personales & 23 & 6 & 0 & 17 \\
Educación, Cultura y Recreación & 7 & 0 & 0 & 7 \\
Comunicaciones y Servicios para vehículos & 7 & 0 & 0 & 7 \\
Vivienda, Servicios de Conservación y Electricidad & 42 & 0 & 0 & 42 \\
Prendas de Vestir, Calzado y Accesorios & 12 & 0 & 0 & 12 \\
Cristalería, Blancos y Utensilios Domésticos & 16 & 3 & 9 & 4 \\
Cuidados de la Salud & 15 & 0 & 0 & 15 \\
Enseres Domésticos y Mantenimiento de la Vivienda & 7 & 0 & 0 & 7 \\
Artículos de Esparcimiento & 9 & 0 & 0 & 9 \\
Transporte & 4 & 0 & 0 & 4 \\
Otros gastos & $\mathbf{3 1 3}$ & $\mathbf{9}$ & $\mathbf{1 3 4}$ & $\mathbf{1 7 0}$ \\
Total & & & & \\
& & & \\
\hline \hline
\end{tabular}

* Los productos que pagan la tasa general son los mismos productos que pagan la tasa impositiva fronteriza cuando el producto es comerciado en una ciudad fronteriza.

\section{Cuadro 2}

Inflación Mensual Promedio del INPC, Porcentajes (Errores Estándar en Paréntesis)

\begin{tabular}{cccc}
\hline \hline & Antes de la Reforma al IVA & \multicolumn{2}{c}{ Después de la Reforma al IVA } \\
& Mar-95 & Abr-95 & May-95 \\
\hline \hline Ciudades fronterizas & 5.71 & 6.58 & 3.58 \\
& $(0.33)$ & $(0.13)$ & $(0.21)$ \\
Ciudades no fronterizas & 5.45 & 7.86 & 4.04 \\
& $(0.12)$ & $(0.13)$ & $(0.06)$ \\
\hline \hline
\end{tabular}




\section{Cuadro 3}

Efecto Inflacionario Mensual en el INPC de la Reforma al IVA Puntos Porcentuales (Errores Estándar en Paréntesis)

\begin{tabular}{lccc}
\hline \hline & $\begin{array}{c}\text { Experimento Desfasado } \\
\text { Feb. Vs. Mar. 95 }\end{array}$ & \multicolumn{2}{c}{ Experimento Natural } \\
& -0.79 & -0.26 & -0.26 \\
& $(0.27)$ & $(0.29)$ & $(0.24)$ \\
\hline \hline Dummy No fronteriza & 0.83 & 0.88 & -2.13 \\
Dummy Después de la & $(0.34)$ & $(0.37)$ & $(0.31)$ \\
Reforma & $\mathbf{0 . 5 3}$ & $\mathbf{1 . 5 3}$ & $\mathbf{0 . 7 2}$ \\
Efecto inflacionario & $(\mathbf{0 . 3 8}$ & $\mathbf{( 0 . 4 1 )}$ & $\mathbf{0 . 3 4 )}$ \\
& 4.88 & 5.71 & 5.71 \\
Constante & $(0.24)$ & $(0.26)$ & $(0.22)$ \\
& & & \\
$\mathrm{R}^{2}$ & 0.5013 & 0.7033 & 0.6280 \\
Observaciones & 92 & 92 & 92 \\
\hline \hline
\end{tabular}

Cuadro 4

Categorías de Gasto: Efecto Inflacionario Mensual de la Reforma al IVA Puntos Porcentuales

\begin{tabular}{|c|c|c|c|c|c|c|}
\hline & "Mar-95 & Abr-95 & May-95 & Jun-95 & Jul-95 & Ago-95 \\
\hline Alimentos, Bebidas y Tabaco & 0.77 & $2.89^{\star *}$ & 0.16 & 0.23 & -1.09 & -0.65 \\
\hline Transporte Público & 0.61 & 4.33 & 2.90 & 3.33 & 1.32 & 0.70 \\
\hline Limpieza y Cuidado de la casa & 0.19 & $3.38^{\star \star}$ & -1.80 & 0.54 & 0.96 & 0.57 \\
\hline Cuidados Personales & -0.51 & $3.92^{*}$ & -0.56 & 1.59 & -0.35 & 0.91 \\
\hline Educación, Cultura y Recreación & $1.97^{\star * *}$ & $2.30^{\star *}$ & -0.44 & -0.51 & -0.42 & -0.34 \\
\hline Comunicaciones y Servicios para vehículos & 1.68 & 1.14 & -1.28 & -1.79 & -0.65 & -0.29 \\
\hline Vivienda, Servicios de Conservación y Electricidad & -2.02 & $3.93^{\star *}$ & 1.49 & $2.87^{\star *}$ & 1.54 & $2.16^{\star *}$ \\
\hline Prendas de Vestir, Calzado y Accesorios & $1.09^{\star \star}$ & $3.70^{*}$ & 0.82 & 0.46 & 0.49 & 0.70 \\
\hline Cristalería, Blancos y Utensilios Domésticos & 0.91 & $2.07^{\star \star \star}$ & -1.36 & -1.24 & 0.91 & 0.44 \\
\hline Cuidados de la Salud & 0.02 & $4.36^{* \star *}$ & 0.71 & 0.20 & -1.60 & 0.22 \\
\hline Enseres Domésticos y Mantenimiento de la Vivienda & -0.52 & $2.53^{* *}$ & -0.54 & -1.11 & -1.20 & -0.99 \\
\hline Artículos de Esparcimiento & 1.25 & 2.09 & -1.23 & -1.97 & -1.76 & -0.70 \\
\hline Transporte & 1.47 & $3.29^{\star *}$ & -0.09 & -0.38 & -1.15 & 0.00 \\
\hline Otros gastos & 0.52 & -0.25 & $-3.47^{\star \star}$ & $-3.64^{* *}$ & -1.71 & -1.69 \\
\hline
\end{tabular}

("significativo al 1\%, ${ }^{\star *}$ al $5 \%,{ }^{\star \star \star}$ al $\left.10 \%\right)$ 
Cuadro 4 (continuación)

\begin{tabular}{lcccrr}
\hline \hline & Sep-95 & Oct-95 & Nov-95 & Dic-95 & No. Obs. \\
\hline \hline Alimentos, Bebidas y Tabaco & -0.10 & -0.46 & -0.33 & -0.56 & 1,288 \\
Transporte Público & 3.04 & 2.32 & 1.96 & 4.25 & 376 \\
Limpieza y Cuidado de la casa & 0.79 & 1.52 & 0.46 & 0.13 & 1,104 \\
Cuidados Personales & 0.78 & 0.97 & 0.32 & 0.84 & 1,380 \\
Educación, Cultura y Recreación & $-1.98^{\star * *}$ & -0.91 & -0.52 & -0.92 & 1,564 \\
Comunicaciones y Servicios para vehículos & -0.41 & -0.57 & -0.77 & -0.56 & 644 \\
Vivienda, Servicios de Conservación y Electricidad & 1.76 & 2.16 & 0.65 & 2.04 & 644 \\
Prendas de Vestir, Calzado y Accesorios & 0.42 & 0.08 & 0.23 & $0.93^{\star * *}$ & 3,830 \\
Cristalería, Blancos y Utensilios Domésticos & -0.86 & $-1.56^{\star \star *}$ & -0.50 & -0.22 & 1,104 \\
Cuidados de la Salud & 0.27 & -0.34 & 1.66 & 0.38 & 368 \\
Enseres Domésticos y Mantenimiento de la Vivienda & -0.75 & -0.62 & -0.40 & -0.05 & 1,380 \\
Artículos de Esparcimiento & -1.63 & $-2.35^{\star *}$ & $-2.24^{\star * *}$ & $-2.46^{\star * *}$ & 644 \\
Transporte & -0.39 & 0.47 & 0.26 & -0.53 & 822 \\
Otros gastos & -1.88 & $-2.97^{\star *}$ & -1.38 & -1.64 & 368 \\
\hline \hline
\end{tabular}

("significativo al $1 \%,{ }^{\star \star}$ al $5 \%,{ }^{\star \star *}$ al $\left.10 \%\right)$

Cuadro 5

Categorías de Gasto: Incidencia del IVA

\begin{tabular}{|c|c|c|c|c|}
\hline & \multicolumn{2}{|c|}{$\begin{array}{c}\text { Cambio en Precio } \\
\text { (Unidades de Indice de Precios) }\end{array}$} & \multicolumn{2}{|c|}{$\begin{array}{c}\text { Incidencia del Impuesto } \\
\text { (Porcentaje) }\end{array}$} \\
\hline & Consumidor & Productor & Consumidor & Productor \\
\hline $\begin{array}{l}\text { Alimentos, Bebidas y Tabaco } \\
\text { Transporte Público }\end{array}$ & $\begin{array}{l}3.33 \\
0.00\end{array}$ & $\begin{array}{l}-1.66 \\
-4.03\end{array}$ & $\begin{array}{r}66.67 \\
0.00\end{array}$ & $\begin{array}{r}33.33 \\
100.00\end{array}$ \\
\hline Limpieza y Cuidado de la casa & 4.11 & -1.23 & 77.00 & 23.00 \\
\hline Cuidados Personales & 4.74 & -0.65 & 87.88 & 12.12 \\
\hline Educación, Cultura y Recreación & 2.52 & -2.56 & 49.64 & 50.36 \\
\hline $\begin{array}{l}\text { Comunicaciones y Servicios para } \\
\text { vehículos }\end{array}$ & 0.00 & -4.88 & 0.00 & 100.00 \\
\hline $\begin{array}{l}\text { Vivienda, Servicios de Conservación y } \\
\text { Electricidad }\end{array}$ & 4.76 & -0.64 & 88.08 & 11.92 \\
\hline Prendas de Vestir, Calzado y Accesorios & 4.23 & -0.83 & 83.67 & 16.33 \\
\hline $\begin{array}{l}\text { Cristalería, Blancos y Utensilios } \\
\text { Domésticos }\end{array}$ & 2.37 & -2.47 & 48.96 & 51.04 \\
\hline Cuidados de la Salud & 5.24 & -.019 & 96.43 & 3.57 \\
\hline $\begin{array}{l}\text { Enseres Domésticos y Mantenimiento } \\
\text { de la Vivienda }\end{array}$ & 2.96 & -2.04 & 59.17 & 40.83 \\
\hline Artículos de Esparcimiento & 0.00 & -4.68 & 0.00 & 100.00 \\
\hline Transporte & 3.97 & -1.32 & 75.11 & 24.89 \\
\hline Otros gastos & 0.00 & -4.46 & 0.00 & 100.00 \\
\hline
\end{tabular}


Cuadro 6

Categorías de Gasto: Factor de Elasticidades Relativas

\begin{tabular}{lc}
\hline \hline & Factor \\
\hline \hline Alimentos, Bebidas y Tabaco & 0.35 \\
Transporte Público & N.A \\
Limpieza y Cuidado de la casa & 0.28 \\
Cuidados Personales & 0.24 \\
Educación, Cultura y Recreación & 0.46 \\
Comunicaciones y Servicios para vehículos & N.A \\
Vivienda, Servicios de Conservación y Electricidad & 0.24 \\
Prendas de Vestir, Calzado y Accesorios & 0.27 \\
Cristalería, Blancos y Utensilios Domésticos & 0.48 \\
Cuidados de la Salud & 0.22 \\
Enseres Domésticos y Mantenimiento de la & 0.39 \\
Vivienda & \\
Artículos de Esparcimiento & N.A \\
Transporte & 0.29 \\
Otros gastos & N.A \\
\hline \hline N.A.:No Aplica
\end{tabular}

$\overline{\text { N.A.: No Aplica }}$

\section{Gráfica 1}

Efecto Inflacionario Mensual en el INPC de la Reforma al IVA (Puntos Porcentuales)

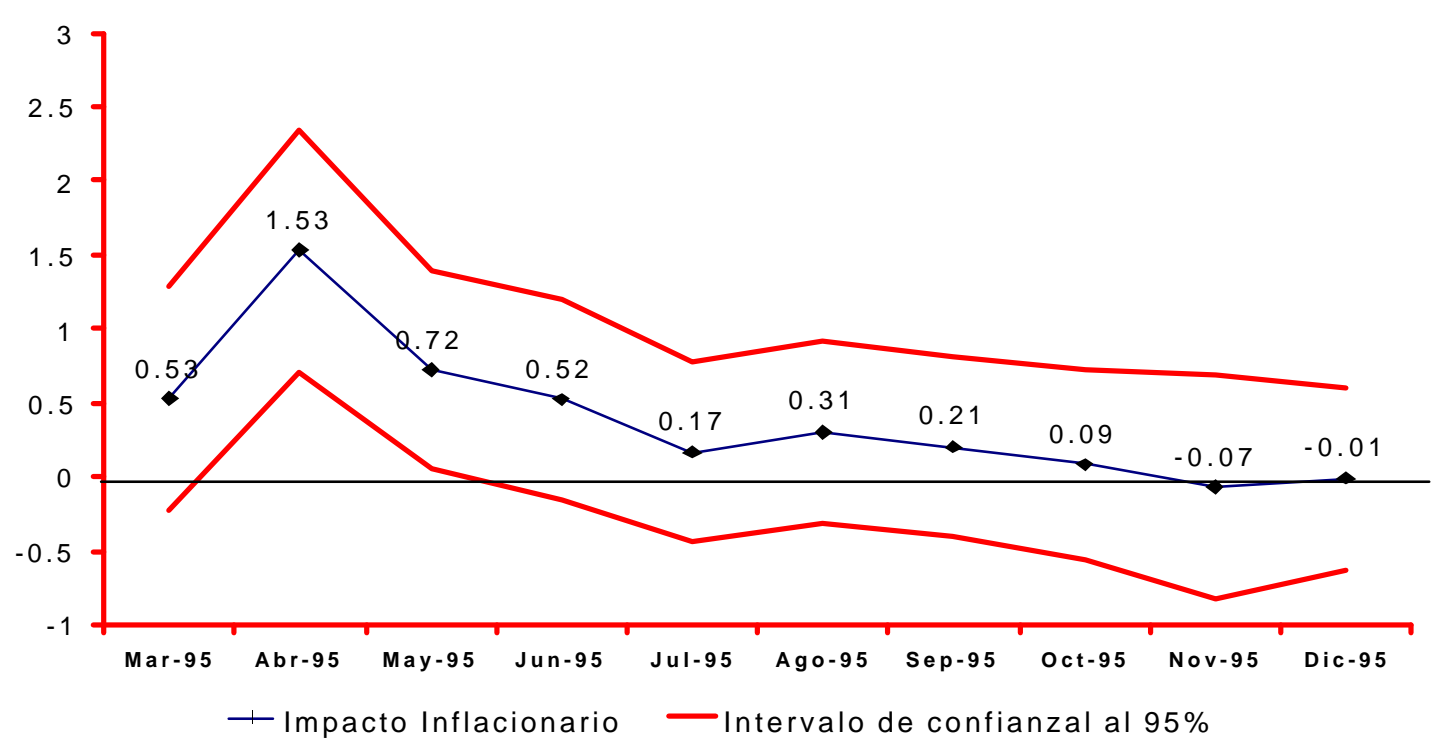




\section{Apéndice 1}

\section{Ciudades No Fronterizas}

Acapulco (Guerrero), Aguascalientes (Aguascalientes), Distrito Federal (México), Campeche (Campeche), Cd. Jiménez (Chihuahua), Colima (Colima), Córdoba (Veracruz), Cortázar (Guanajuato), Cuernavaca (Morelos), Culiacán (Sinaloa), Chihuahua (Chihuahua), Durango (Durango), Fresnilllo (Zacatecas), Guadalajara (Jalisco), Hermosillo (Sonora), Huatabambo (Sonora), Iguala (Guerrero), Jacona (Michoacán), León (Guanajuato), Mérida (Yucatán), Monclova (Coahuila), Monterrey (Nuevo León), Morelia (Michoacán), Oaxaca (Oaxaca), Puebla (Puebla), Querétaro (Querétaro), San Andrés Tuxtla (Veracruz), San Luis Potosí (San Luis Potosí), Tampico (Tampico), Tehuantepec (Oaxaca), Tepatitlán (Jalisco), Tepic (Nayarit), Tlaxcala (Tlaxcala), Toluca (Estado de México), Torreón (Coahuila), Tulancingo (Hidalgo), Veracruz (Veracruz), Villahermosa (Tabasco).

\section{Ciudades Fronterizas}

Cd. Acuña (Coahuila), Cd. Juárez (Chihuahua), Chetumal (Quinatana Roo), La Paz (Baja California Sur), Matamoros (Tampico), Mexicali (Baja California), Tapachula (Chiapas) y Tijuana (Baja California). 
Apéndice 2. Efecto Mensual Inflacionario de la Reforma del IVA por Producto

Cuadro A1. Categorías de Gasto: Efecto Mensual Inflacionario de la Reforma del IVA (Puntos Porcentuales)

\begin{tabular}{|c|c|c|c|c|c|c|c|c|c|c|}
\hline & Marzo & & Abril & & Mayo & & Junio & & Julio & \\
\hline \multicolumn{11}{|l|}{ Alimentos, bebidas y tabaco } \\
\hline Carnitas de Puerco & -0.89 & & -2.52 & & -2.30 & & -1.65 & & -2.74 & \\
\hline Pollo Rostizado & 2.70 & & -0.60 & & 5.08 & $* * *$ & 2.25 & & -1.48 & \\
\hline Barbacoa de Borrego & 1.29 & & 0.10 & & -0.50 & & 0.04 & & 0.85 & \\
\hline Otros alimentos preparados & -3.64 & & 1.83 & & 1.04 & & 4.01 & & 0.61 & \\
\hline Refrescos embotellados & 1.32 & & 4.02 & & -0.24 & & 0.55 & & 1.62 & \\
\hline Jugos o néctares enlatados & 2.41 & & 1.44 & & -5.57 & & -4.29 & & -1.50 & \\
\hline Concentrado y polvo para preparar agua & 0.42 & & 3.02 & & -0.82 & & 2.31 & & -0.08 & \\
\hline Cerveza & -1.52 & & 4.18 & & 0.72 & & 0.78 & & 1.35 & \\
\hline Brandy & 2.75 & & 4.13 & $* * *$ & 1.54 & & 0.95 & & -2.32 & \\
\hline Tequila & -0.82 & & 3.67 & $* * *$ & 0.00 & & 0.47 & & -0.41 & \\
\hline Ron & 5.53 & $* *$ & 0.65 & & -1.85 & & -3.11 & & -7.74 & $* *$ \\
\hline Vinos de mesa & 4.40 & & 4.85 & & -2.02 & & -4.58 & $* *$ & -5.40 & $* * *$ \\
\hline Otros licores & -1.27 & & 10.35 & $* *$ & 7.19 & $* * *$ & 5.69 & $* *$ & 2.66 & \\
\hline Cigarros & -1.85 & & 5.29 & $* *$ & 0.01 & & -0.12 & & -0.70 & \\
\hline \multicolumn{11}{|l|}{ Transporte público } \\
\hline Metro & N.A. & & N.A. & & N.A. & & N.A. & & N.A. & \\
\hline Autobús & -2.64 & & 16.54 & $* *$ & 12.62 & $* *$ & 10.92 & $* *$ & 7.67 & \\
\hline Colectivo(pesero) & 1.48 & & 6.58 & & 4.76 & & 7.40 & & 3.04 & \\
\hline Taxi, radio taxi (sitio) & 5.05 & & -4.62 & & -5.43 & & -5.38 & & -4.86 & \\
\hline Autobús foráneo & 4.58 & $* * *$ & -7.55 & $* *$ & -6.38 & $* *$ & -5.65 & $* *$ & -7.20 & $* *$ \\
\hline \multicolumn{11}{|l|}{ Limpieza y cuidado de la casa } \\
\hline Detergentes y similares & 4.68 & & 1.41 & & -2.91 & & -8.58 & $* *$ & -1.27 & \\
\hline Jabón de barra & 1.71 & & 3.77 & & -5.67 & & -4.76 & & -3.38 & \\
\hline Blanqueadores y limpiadores & -3.56 & & 4.98 & $* * *$ & -2.67 & & 0.03 & & 0.37 & \\
\hline Papel sanitario & -1.33 & & -0.12 & & 3.26 & & 3.49 & & -1.41 & \\
\hline Servilletas y papel absorbente & 0.93 & & -5.22 & & -0.94 & & -4.09 & & -2.46 & \\
\hline Escobas y trapeadores & 7.16 & $* *$ & 0.20 & & -7.92 & $* * *$ & -4.47 & & -2.48 & \\
\hline Cerillos & -3.16 & & 2.00 & & -12.86 & $* *$ & 2.21 & & 0.15 & \\
\hline Pilas & -15.74 & $* *$ & 12.95 & & 16.24 & $* * *$ & 23.06 & $* *$ & 20.70 & $* * *$ \\
\hline Focos & -4.37 & & 9.88 & $* *$ & 2.31 & & 4.96 & & 10.80 & $* *$ \\
\hline Insecticidas & 2.64 & & 5.81 & & -2.60 & & 0.29 & & -3.22 & \\
\hline Desodorante ambiental y sanitario & 8.57 & $* *$ & 5.47 & & -7.46 & $* *$ & -2.74 & & -2.85 & \\
\hline Tintorería & 4.79 & $* * *$ & -0.54 & & -0.40 & & -2.93 & & -3.40 & \\
\hline \multicolumn{11}{|l|}{ Cuidados Personales } \\
\hline Jabón de tocador & -14.68 & $* *$ & 16.51 & $* *$ & 8.05 & & 9.97 & $* *$ & 10.73 & $* * *$ \\
\hline Lociones y perfumes & 2.46 & & 3.45 & & -2.17 & & -0.84 & & -0.14 & \\
\hline Pasta dental y enjuage bucal & -0.80 & & 2.90 & & 0.47 & & 0.03 & & -1.67 & \\
\hline Shampoos, tintes y enjuagues & 3.04 & & 1.36 & & -7.11 & $* *$ & -5.19 & $* *$ & -7.26 & $* *$ \\
\hline Desodorante & 5.64 & & -0.62 & & -7.18 & $* * *$ & 0.14 & & -4.96 & $* * *$ \\
\hline Crema, brillantina y crema para afeitar & 0.38 & & 4.86 & & -0.99 & & 3.89 & & 3.05 & \\
\hline Navajas y rastrillos para afeitar & 0.23 & & 7.87 & & -1.65 & & -0.58 & & -0.89 & \\
\hline Polvo y maquillaje facial & 5.84 & & -3.48 & & -3.41 & & -3.92 & & -2.52 & \\
\hline Pañuelos desechables & -4.98 & & 7.89 & $* * *$ & 1.68 & & 5.48 & & 1.63 & \\
\hline Pañales desechables & 9.99 & & 1.73 & & -8.85 & & 0.31 & & -7.46 & \\
\hline Toallas sanitarias & 7.77 & $* *$ & -3.47 & & -1.51 & & -1.62 & & -1.85 & \\
\hline Otros: esmaltes y limas para uñas, pasadores, et & -4.02 & & 1.80 & & 4.49 & & 5.98 & & 0.50 & \\
\hline Corte de cabello y peinado & -0.88 & & 1.13 & & -0.76 & & -1.22 & & -6.52 & $* * *$ \\
\hline Baños y masajes & -17.08 & $* *$ & 17.55 & $* *$ & 13.09 & $* *$ & 12.20 & $* *$ & 13.20 & $* *$ \\
\hline Salón de belleza & -0.58 & & -0.64 & & -2.60 & & -0.77 & & -1.09 & \\
\hline
\end{tabular}


Cuadro A1 (Continuación)

\begin{tabular}{|c|c|c|c|c|c|c|c|c|c|c|c|}
\hline & Agosto & & Septiembre & & Octubre & & Noviembre & & Diciembre & & Muestra \\
\hline \multicolumn{12}{|l|}{ Alimentos, bebidas y tabaco } \\
\hline Carnitas de Puerco & -4.85 & $* * *$ & -0.70 & & -2.57 & & -3.35 & & -0.50 & & 92 \\
\hline Pollo Rostizado & -0.93 & & 0.64 & & 1.55 & & 1.19 & & 0.70 & & 92 \\
\hline Barbacoa de Borrego & -4.26 & $* * *$ & -0.39 & & 1.02 & & -0.18 & & 0.23 & & 92 \\
\hline Otros alimentos preparados & 2.40 & & 3.01 & & 2.60 & & 1.75 & & 0.61 & & 92 \\
\hline Refrescos embotellados & -1.14 & & -0.42 & & -0.41 & & 0.25 & & -2.22 & & 92 \\
\hline Jugos o néctares enlatados & -2.09 & & -2.46 & & -1.56 & & -2.83 & & -2.66 & & 92 \\
\hline Concentrado y polvo para preparar agua & 1.23 & & -0.24 & & -4.68 & & -0.08 & & -3.31 & & 92 \\
\hline Cerveza & 1.82 & & 0.02 & & 0.67 & & -0.26 & & 1.03 & & 92 \\
\hline Brandy & -2.09 & & -1.98 & & -0.78 & & -1.65 & & -0.44 & & 92 \\
\hline Tequila & 0.34 & & 1.15 & & 1.36 & & 1.21 & & 1.87 & & 92 \\
\hline Ron & -4.39 & $* * *$ & -4.51 & $* *$ & -5.50 & $* *$ & -4.91 & $* *$ & -5.15 & $* *$ & 92 \\
\hline Vinos de mesa & -2.74 & & -2.11 & & -2.53 & & -2.41 & & -3.44 & & 92 \\
\hline Otros licores & 4.86 & & 5.63 & $* *$ & 3.24 & & 5.22 & & 5.23 & & 92 \\
\hline Cigarros & 2.77 & & 0.90 & & 1.21 & & 1.49 & & 0.21 & & 92 \\
\hline \multicolumn{12}{|l|}{ Transporte público } \\
\hline Metro & N.A. & & N.A. & & N.A. & & N.A. & & N.A. & & 10 \\
\hline Autobús & 6.01 & & 10.24 & $* * *$ & 8.59 & & 9.03 & & 10.41 & & 90 \\
\hline Colectivo(pesero) & 2.90 & & 4.72 & & 3.10 & & 3.48 & & 5.12 & & 92 \\
\hline Taxi, radio taxi (sitio) & -6.38 & $* * *$ & -3.42 & & -3.84 & & -5.59 & & -2.25 & & 92 \\
\hline Autobús foráneo & -5.95 & $* *$ & -5.50 & $* *$ & -5.14 & $* *$ & -5.58 & ** & -4.29 & & 92 \\
\hline \multicolumn{12}{|l|}{ Limpieza y cuidado de la casa } \\
\hline Detergentes y similares & -3.07 & & -4.01 & & -2.12 & & -1.41 & & -2.27 & & 92 \\
\hline Jabón de barra & -2.86 & & -1.80 & & -0.49 & & -4.80 & & -2.52 & & 92 \\
\hline Blanqueadores y limpiadores & -0.65 & & -2.06 & & 1.45 & & 0.75 & & 1.24 & & 92 \\
\hline Papel sanitario & -1.02 & & 0.49 & & 2.53 & & 1.00 & & -0.67 & & 92 \\
\hline Servilletas y papel absorbente & -1.35 & & -1.70 & & -2.48 & & -3.14 & & -4.34 & & 92 \\
\hline Escobas y trapeadores & -3.71 & & -5.73 & $* *$ & -4.07 & & -5.29 & *** & -4.18 & & 92 \\
\hline Cerillos & -0.96 & & -0.52 & & -2.50 & & -7.67 & $* *$ & -6.57 & & 92 \\
\hline Pilas & 19.22 & $* *$ & 21.70 & $* *$ & 16.99 & $* *$ & 21.78 & $* *$ & 19.13 & $* *$ & 92 \\
\hline Focos & 2.36 & & 3.01 & & 7.36 & $* * *$ & 8.02 & $* *$ & 6.68 & & 92 \\
\hline Insecticidas & 1.65 & & -0.97 & & -1.38 & & -1.64 & & -0.31 & & 92 \\
\hline Desodorante ambiental y sanitario & -0.61 & & -0.70 & & 3.35 & & -1.24 & & -1.94 & & 92 \\
\hline Tintorería & -2.11 & & 1.80 & & -0.45 & & -0.82 & & -2.64 & & 92 \\
\hline \multicolumn{12}{|l|}{ Cuidados Personales } \\
\hline Jabón de tocador & 10.94 & $* * *$ & 11.83 & $* *$ & 10.81 & $* * *$ & 10.09 & $* *$ & 9.85 & $* * *$ & 92 \\
\hline Lociones y perfumes & -1.29 & & -0.33 & & 0.12 & & -1.49 & & -1.66 & & 92 \\
\hline Pasta dental y enjuage bucal & -1.68 & & 0.04 & & 0.30 & & -0.13 & & -0.59 & & 92 \\
\hline Champús, tintes y enjuagues & -2.11 & & -3.29 & & -4.36 & $* *$ & -3.84 & $* *$ & -1.88 & & 92 \\
\hline Desodorante & -3.26 & & -1.45 & & -0.37 & & -3.73 & & -1.59 & & 92 \\
\hline Crema, brillantina y crema para afeitar & 0.04 & & 2.80 & & 3.37 & & -1.98 & & 2.13 & & 92 \\
\hline Navajas y rastrillos para afeitar & 3.02 & & -3.23 & & -4.62 & & -4.57 & & 1.90 & & 92 \\
\hline Polvo y maquillaje facial & -1.72 & & -2.94 & & -1.56 & & -2.92 & & -2.41 & & 92 \\
\hline Pañuelos desechables & 5.18 & & 4.27 & & 2.53 & & 3.87 & & 1.33 & & 92 \\
\hline Pañales desechables & -5.81 & & -4.65 & & -4.55 & & -3.56 & & -5.13 & & 92 \\
\hline Toallas sanitarias & -1.66 & & -1.38 & & -1.23 & & -0.20 & & -0.44 & & 92 \\
\hline Otros: esmaltes y limas para uñas, pasadores, ef & 4.29 & & 1.56 & & 3.75 & & 6.69 & $* *$ & 4.39 & & 92 \\
\hline Corte de cabello y peinado & -3.20 & $* * *$ & -3.10 & & -1.10 & & -3.52 & ** & -3.83 & & 92 \\
\hline Baños y masajes & 11.66 & $* *$ & 12.54 & $* *$ & 12.47 & $* *$ & 11.68 & ** & 11.95 & $* *$ & 92 \\
\hline Salón de belleza & -0.75 & & -0.94 & & -1.02 & & -1.62 & & -1.47 & & 92 \\
\hline
\end{tabular}

(* significativo al $1 \%, * *$ al $5 \%, * * *$ al $10 \%)$ 
Cuadro A1 (Continuación)

\begin{tabular}{|c|c|c|c|c|c|c|c|c|c|c|}
\hline & Marzo & & Abril & & Mayo & & Junio & & Julio & \\
\hline \multicolumn{11}{|l|}{ Educación, cultura y recreación } \\
\hline Estudios técnicos y de lenguas & 0.58 & & 1.15 & & 0.23 & & 0.53 & & 0.11 & \\
\hline Libros para la escuela & 1.76 & & 0.22 & & -0.94 & & -3.19 & & -2.90 & \\
\hline Cuadernos, carpetas, etc. & 4.23 & & 10.86 & $* * *$ & 2.47 & & 2.50 & & 0.17 & \\
\hline Lápices, plumas, etc. & -10.66 & $* * *$ & 10.38 & $* *$ & 6.60 & & 14.94 & $* *$ & 11.61 & $* *$ \\
\hline Periódicos y revistas & -7.94 & & 3.08 & & 1.38 & & 8.26 & & 4.12 & \\
\hline Revistas & -5.34 & & 3.66 & & 1.56 & & -0.46 & & 1.16 & \\
\hline Audio cassetes, discos y discos compactos & 5.83 & & 5.56 & & 0.34 & & -4.08 & & -0.76 & \\
\hline Otros libros & 3.68 & & -1.18 & & -2.93 & & -5.13 & & -2.41 & \\
\hline Cines & 2.24 & & -4.35 & & 2.28 & & 0.72 & & 3.17 & \\
\hline Centros nocturnos & 9.64 & $* *$ & 0.63 & & -0.41 & & -4.71 & & -3.89 & \\
\hline Hoteles & -0.26 & & 2.74 & $* *$ & 0.57 & & -0.67 & & -1.31 & \\
\hline Clubes deportivos & 9.56 & $* *$ & 3.41 & & -1.26 & & -6.83 & $* *$ & -0.69 & \\
\hline Otros gastos de recreación: circos, museos, etc. & 4.93 & & -2.88 & & -4.93 & & -2.01 & & -6.72 & \\
\hline Restaurantes, cantinas y similares & 4.25 & $* *$ & 2.51 & & 0.85 & & -2.77 & & -2.91 & \\
\hline Almuerzos & 3.02 & & 1.27 & & -8.79 & $* *$ & -2.99 & & -2.26 & \\
\hline Cafeterías & 8.40 & $* *$ & 1.27 & & -2.23 & & -1.77 & & -0.85 & \\
\hline Cantinas & -0.34 & & 0.80 & & -2.34 & & -0.92 & & -2.85 & \\
\hline \multicolumn{11}{|l|}{ Comunicaciones y servicios para vehículos } \\
\hline Teléfono particular & -0.16 & & 4.47 & $*$ & 0.90 & & -0.15 & & 0.20 & \\
\hline Servicio telefónico local & 0.25 & & -0.49 & & -0.25 & & -0.25 & & -0.25 & \\
\hline Larga distancia nacional & 0.34 & & -0.29 & & -0.33 & & -0.34 & & -0.33 & \\
\hline Larga distancia internacional & 0.16 & & -0.27 & & -0.17 & & -0.16 & & -0.16 & \\
\hline Gasolina, diesel o gas & -4.71 & $* *$ & 2.97 & $* * *$ & 1.17 & & 0.93 & & 0.36 & \\
\hline Aceites y lubricantes & 6.19 & & 0.20 & & -8.12 & $* * *$ & -5.40 & & -5.73 & $* * *$ \\
\hline Pensión y estacionamiento & 9.69 & $* * *$ & 1.38 & & -2.14 & & -7.17 & & 1.40 & \\
\hline \multicolumn{11}{|l|}{ Vivienda y servicios de conservación } \\
\hline Vivienda propia & -0.02 & & 1.31 & $* *$ & 0.38 & & -0.01 & & 0.31 & \\
\hline Mantenimiento y servicios de conservación & 2.70 & & -0.38 & & -0.37 & & 1.63 & & -0.78 & \\
\hline Vivienda rentada o alquilada & 0.59 & & 0.19 & & 0.51 & & 0.43 & & 0.53 & \\
\hline Energiá eléctrica & -2.46 & $* *$ & 2.40 & & 8.09 & $* * *$ & 0.87 & & 0.00 & \\
\hline Gas doméstico & -1.36 & & 7.08 & $* *$ & -1.02 & & 1.13 & & 2.27 & \\
\hline Velas y veladoras & 2.06 & & 0.72 & & -4.86 & & -2.24 & & -2.02 & \\
\hline Otros combustibles: cartón, papel, etc. & -15.67 & $* *$ & 16.22 & $* *$ & 7.69 & & 18.30 & $* *$ & 10.47 & $* * *$ \\
\hline
\end{tabular}




\section{Cuadro A1 (continuación)}

\begin{tabular}{|c|c|c|c|c|c|c|c|c|c|c|c|}
\hline & Agosto & & Septiembre & & Octubre & & Noviembre & & Diciembre & & Muestra \\
\hline \multicolumn{12}{|l|}{ Educación, cultura y recreación } \\
\hline Estudios técnicos y de lenguas & 1.32 & & -4.16 & & 0.11 & & -0.02 & & 0.49 & & 92 \\
\hline Libros para la escuela & 0.75 & & -14.33 & $* *$ & -4.59 & $* * *$ & -3.66 & & -3.67 & & 92 \\
\hline Cuadernos, carpetas, etc. & -1.50 & & -4.36 & & -2.14 & & 0.27 & & -1.36 & & 92 \\
\hline Lápices, plumas, etc. & 3.32 & & 6.56 & $* * *$ & 9.47 & $* *$ & 10.63 & *** & 6.57 & & 92 \\
\hline Periódicos y revistas & 5.45 & & 2.25 & & 5.94 & & 2.80 & & 5.42 & & 92 \\
\hline Revistas & 0.70 & & 1.73 & & 3.37 & & 1.89 & & 0.98 & & 92 \\
\hline Audio cassetes, discos y discos compactos & 0.86 & & -1.31 & & -1.45 & & 1.26 & & -1.35 & & 92 \\
\hline Otros libros & 1.42 & & -3.21 & & -3.56 & & -2.84 & & -3.79 & & 92 \\
\hline Cines & 1.26 & & 2.02 & & -0.05 & & 1.54 & & 1.81 & & 92 \\
\hline Centros nocturnos & -4.88 & & -4.70 & & -8.66 & $* *$ & -2.44 & & -4.26 & & 92 \\
\hline Hoteles & 0.82 & & 0.26 & & -0.24 & & -1.42 & $* *$ & -0.22 & & 92 \\
\hline Clubes deportivos & -7.45 & $* * *$ & -2.71 & & -3.24 & & -4.24 & & -8.20 & $* *$ & 92 \\
\hline Otros gastos de recreación: circos, museos, etc. & -0.44 & & -4.73 & & -2.38 & & 0.13 & & -0.39 & & 92 \\
\hline Restaurantes, cantinas y similares & -1.57 & & -0.85 & & -2.11 & & -2.67 & & -0.10 & & 92 \\
\hline Almuerzos & -3.26 & & -1.20 & & -1.42 & & -4.51 & $* *$ & -2.09 & & 92 \\
\hline Cafeterías & -0.58 & & -1.64 & & -1.44 & & -2.70 & & -2.71 & & 92 \\
\hline Cantinas & -1.95 & & -3.20 & & -3.07 & & -2.88 & & -2.76 & & 92 \\
\hline \multicolumn{12}{|l|}{ Comunicaciones y servicios para vehículos } \\
\hline Teléfono particular & 0.12 & & 0.21 & & -0.05 & & 0.08 & & 0.17 & & 92 \\
\hline Servicio telefónico local & -0.25 & & -0.25 & & -0.25 & & -0.25 & & -0.25 & & 92 \\
\hline Larga distancia nacional & -0.34 & & -0.34 & & -0.34 & & -0.34 & & -0.34 & & 92 \\
\hline Larga distancia internacional & -0.16 & & -0.16 & & -0.16 & & -0.16 & & -0.16 & & 92 \\
\hline Gasolina, diesel o gas & 0.91 & & 0.91 & & 1.05 & & 0.99 & & 0.78 & & 92 \\
\hline Aceites y lubricantes & -3.04 & & -3.44 & & -5.00 & & -5.19 & $* *$ & -5.02 & & 92 \\
\hline Pensión y estacionamiento & 0.76 & & 0.18 & & 0.77 & & -0.55 & & 0.92 & & 92 \\
\hline \multicolumn{12}{|l|}{ Vivienda y servicios de conservación } \\
\hline Vivienda propia & 0.60 & & 0.23 & & 0.30 & & -0.17 & & 0.06 & & 92 \\
\hline Mantenimiento y servicios de conservación & 0.51 & & 0.26 & & -0.32 & & -1.35 & & -1.03 & & 92 \\
\hline Vivienda rentada o alquilada & 0.78 & & 0.42 & & 0.28 & & -0.43 & & -0.38 & & 92 \\
\hline Energiá eléctrica & -3.28 & $* *$ & 0.01 & & -3.43 & & -10.27 & & -0.02 & & 92 \\
\hline Gas doméstico & 1.05 & & -0.10 & & 1.40 & & 1.78 & & -3.39 & & 92 \\
\hline Velas y veladoras & -0.40 & & -3.49 & & 2.94 & & -2.86 & & 0.70 & & 92 \\
\hline Otros combustibles: cartón, papel, etc. & 15.85 & $* *$ & 14.98 & $* *$ & 14.00 & $* *$ & 17.85 & $* *$ & 18.35 & $* *$ & 92 \\
\hline
\end{tabular}

(* significativo al 1\%,**al 5\%, *** al 10\%) 


\section{Cuadro A1 (continuación)}

\begin{tabular}{|c|c|c|c|c|c|c|c|c|c|}
\hline & Marzo & Abril & & Mayo & & Junio & & Julio & \\
\hline \multicolumn{10}{|l|}{ Prendas de vestir, calzado y accesorios } \\
\hline Pantalones para hombre de mezclilla & 4.71 & 10.32 & $* *$ & 6.57 & & -0.53 & & 3.17 & \\
\hline Pantalones para hombre de fibras sintéticas & $9.56 * *$ & 5.57 & $* *$ & 1.43 & & 4.34 & & 0.02 & $* *$ \\
\hline Pantalones para mujer de mezclilla & -1.84 & 4.32 & & -0.98 & & 1.86 & & 0.87 & \\
\hline Pantalones para mujer de fibras sintéticas & 1.16 & 2.65 & & -4.96 & $* * *$ & 1.88 & & 0.52 & \\
\hline Chamarras y chaquetas & -0.32 & 5.43 & $* *$ & 2.32 & & 0.46 & & 1.91 & \\
\hline Blusas y playeras para mujer & 0.79 & 1.77 & & -6.03 & $* * *$ & -2.19 & & -1.49 & \\
\hline Trajes & 2.46 & 7.21 & & 2.80 & & 3.27 & & -0.69 & \\
\hline Vestidos & 1.70 & 4.16 & & -0.07 & & 1.25 & & 0.04 & \\
\hline Conjuntos para mujer & -2.15 & 3.84 & & 4.19 & & -1.75 & & -2.36 & \\
\hline Faldas & 1.75 & 4.66 & $* * *$ & -0.93 & & 1.65 & & 1.30 & \\
\hline Abrigos & 6.28 & -2.50 & & -4.96 & & -2.60 & & -6.10 & \\
\hline Suéteres & 1.07 & 5.59 & & 11.09 & $* *$ & 6.34 & $* *$ & 5.72 & $* * *$ \\
\hline Calzoncillos y truzas & -3.99 & 6.52 & $* * *$ & 7.12 & $* *$ & 2.87 & & 5.76 & $* *$ \\
\hline Camisetas y playeras & 5.93 & 4.53 & & 5.26 & & -2.82 & & 7.04 & \\
\hline Calcetines & 8.37 & 8.60 & $* *$ & 3.82 & & -5.73 & & 1.73 & \\
\hline Calcetas y mallas & -1.55 & -0.50 & & -2.88 & & 2.54 & & 4.86 & \\
\hline Pantaletas & 2.10 & 1.43 & & 0.01 & & -0.79 & & -1.00 & \\
\hline Medias, pantimedias y tobimedias & -3.08 & 4.03 & & 0.91 & & -0.93 & & -1.06 & \\
\hline Calzoncillos para niño & 4.24 & 0.43 & & -2.03 & & -0.05 & & -2.27 & \\
\hline Vestidos para niña & 2.68 & 5.34 & $* *$ & 2.44 & & -1.54 & & 1.18 & \\
\hline Pantaletas para niña & 3.17 & 2.93 & & 0.96 & & -0.13 & & 2.19 & \\
\hline Pijamas y batas & 0.58 & 3.66 & & 0.35 & & 0.83 & & -1.43 & \\
\hline Otras prendas para hombre (corbatas, etc.) & -5.41 & 7.46 & $* *$ & 0.57 & & 4.92 & & 6.11 & \\
\hline Otras prendas de vestir & 0.39 & 5.14 & & -0.98 & & -3.55 & & -6.15 & $* * *$ \\
\hline Pantalones de niño de fibras sintéticas & -2.69 & 7.87 & $* *$ & 4.30 & & 4.72 & & 5.52 & \\
\hline Pantalones de niño de algodón & -2.00 & 0.91 & & -0.18 & & 1.51 & & 1.29 & \\
\hline Blusas para niño & $-8.55 * *$ & 7.27 & & 12.65 & $* *$ & 11.05 & $* *$ & 6.38 & \\
\hline Playeras para bebé & 2.22 & -0.82 & & 0.16 & & -1.99 & & 0.68 & \\
\hline Suéter para niño & -1.68 & 3.03 & & 1.57 & & 2.62 & & -1.74 & \\
\hline Suéter para niña & -1.87 & 3.27 & & 1.77 & & 1.96 & & 3.84 & \\
\hline Uniformes escolares para niño & 4.84 & 0.33 & & -0.89 & & -5.54 & & -3.28 & \\
\hline Uniformes escolares para niña & -1.32 & -0.76 & & -2.40 & & 2.71 & & 0.99 & \\
\hline Zapatos para hombre & 2.57 & 1.95 & & -2.42 & & -4.17 & $* *:$ & -4.60 & $* * *$ \\
\hline Zapatos para mujer & 2.70 & 4.11 & $* * *$ & -0.91 & & -1.72 & & -1.36 & \\
\hline Zapatos para niño & -0.02 & 5.57 & $* *$ & -0.91 & & 1.44 & & 0.36 & \\
\hline Tenis & 1.35 & 7.10 & $* *$ & 0.18 & & 2.71 & & 1.40 & \\
\hline Otro tipo de calzado: huaraches, sandalias, etc. & 4.29 & 3.87 & & 1.44 & & -0.33 & & -0.54 & \\
\hline Servicio de limpieza y reparación de calzado & -1.00 & -0.64 & & 1.41 & & 1.59 & & -0.26 & \\
\hline Sombreros, gorros y cachuchas & 5.08 & 3.53 & & -2.34 & & -5.17 & & -3.93 & \\
\hline Bolsas, portafolios y cinturones & 1.31 & 3.41 & & -0.64 & & 0.19 & & 0.23 & \\
\hline Joyería y joyería de fantasía & -0.08 & 0.02 & & 0.06 & & 0.07 & & 0.07 & \\
\hline Relojes & 3.17 & 2.50 & & -4.52 & & -2.42 & & -5.95 & \\
\hline
\end{tabular}

(* significativo at $1 \%, * *$ at $5 \%, * * *$ at $10 \%)$ 


\section{Cuadro A1 (continuación)}

\begin{tabular}{|c|c|c|c|c|c|c|c|c|c|c|c|}
\hline \multirow[b]{2}{*}{ Prendas de vestir, calzado y accesorios } & \multicolumn{2}{|l|}{ Agosto } & \multicolumn{2}{|l|}{ Septiembre } & \multicolumn{2}{|l|}{ Octubre } & \multicolumn{2}{|l|}{ Noviembre } & \multicolumn{2}{|l|}{ Diciembre } & \multirow[t]{2}{*}{ Muestra } \\
\hline & & & & & & & & & & & \\
\hline Pantalones para hombre de mezclilla & -1.15 & & 1.55 & & 6.41 & $* *$ & 5.93 & $* *$ & 6.90 & $* *$ & 92 \\
\hline Pantalones para hombre de fibras sintéticas & 0.62 & $* *$ & 1.10 & & -0.02 & & -0.11 & & 3.00 & & 92 \\
\hline Pantalones para mujer de mezclilla & -1.04 & & -0.84 & & -0.23 & & -0.32 & & -2.11 & & 90 \\
\hline Pantalones para mujer de fibras sintéticas & -2.67 & & -0.78 & & -1.29 & & -3.29 & $* *$ & -6.65 & $* *$ & 92 \\
\hline Chamarras y chaquetas & 1.06 & & 2.49 & & 1.35 & & 2.71 & & 0.20 & & 92 \\
\hline Blusas y playeras para mujer & -1.26 & & -1.53 & & -5.74 & $* * *$ & -2.22 & & -1.84 & & 92 \\
\hline Trajes & 2.07 & & 3.18 & & -0.98 & & 1.84 & & 1.55 & & 88 \\
\hline Vestidos & -0.13 & & 0.25 & & 0.58 & & -0.94 & & -0.83 & & 92 \\
\hline Conjuntos para mujer & 1.73 & & 1.61 & & 3.47 & & 2.70 & & 0.82 & & 90 \\
\hline Faldas & 1.80 & & 1.69 & & 0.66 & & 2.06 & & 0.10 & & 92 \\
\hline Abrigos & -3.91 & & -3.56 & & -3.27 & & -3.77 & & -6.42 & & 82 \\
\hline Suéteres & 7.59 & $* *$ & 6.96 & $* * *$ & 4.78 & & 4.28 & & 3.86 & & 88 \\
\hline Calzoncillos y truzas & 3.23 & & 5.05 & & 0.75 & & 0.59 & & 5.44 & $* *$ & 92 \\
\hline Camisetas y playeras & 3.16 & & 4.87 & & 2.27 & & 4.14 & & 6.58 & & 92 \\
\hline Calcetines & 2.99 & & 1.98 & & 4.77 & & 1.98 & & 6.31 & & 92 \\
\hline Calcetas y mallas & 1.03 & & 2.71 & & 1.83 & & -3.27 & & -1.06 & & 92 \\
\hline Pantaletas & -4.04 & $* * *$ & -3.23 & & -2.73 & & -1.76 & & -0.08 & & 92 \\
\hline Medias, pantimedias y tobimedias & 1.49 & & -1.99 & & -0.45 & & 1.79 & & 0.47 & & 92 \\
\hline Calzoncillos para niño & -1.20 & & -0.57 & & -1.29 & & -8.91 & $* *$ & -2.72 & & 92 \\
\hline Vestidos para niña & 0.84 & & 1.62 & & 2.30 & & 3.50 & & -1.27 & & 92 \\
\hline Pantaletas para niña & -1.27 & & 0.00 & & 2.09 & & 0.61 & & -0.10 & & 92 \\
\hline Pijamas y batas & 1.48 & & 1.37 & & -1.84 & & -3.30 & & 2.39 & & 92 \\
\hline Otras prendas para hombre (corbatas, etc.) & 4.90 & & -0.04 & & 5.84 & $* * *$ & 3.67 & & 4.64 & & 88 \\
\hline Otras prendas de vestir & -5.07 & & -8.08 & $* *$ & -9.29 & $* *$ & -5.39 & & -1.60 & & 92 \\
\hline Pantalones de niño de fibras sintéticas & 4.40 & & 2.64 & & 8.23 & $* * *$ & 4.77 & $* *$ & 6.25 & $* *$ & 92 \\
\hline Pantalones de niño de algodón & 1.97 & & 3.35 & & 0.42 & & 2.78 & & 2.32 & & 92 \\
\hline Blusas para niño & 6.76 & $* * *$ & 10.45 & $* *$ & 7.56 & $* * *$ & 7.37 & $* *:$ & 6.51 & $* * *$ & 92 \\
\hline Playeras para bebé & -1.32 & & -2.43 & & -0.88 & & -1.46 & & -2.20 & & 92 \\
\hline Suéter para niño & 0.37 & & -0.24 & & -0.05 & & 3.39 & & 7.51 & $* *$ & 88 \\
\hline Suéter para niña & 3.06 & & 3.58 & & -1.14 & & 2.49 & & 4.25 & & 88 \\
\hline Uniformes escolares para niño & -0.71 & & -4.37 & & -4.24 & & -3.68 & & -3.17 & & 92 \\
\hline Uniformes escolares para niña & 6.48 & $* *$ & -5.53 & & -5.11 & $* *$ & -1.61 & & 2.83 & & 92 \\
\hline Zapatos para hombre & -1.52 & & -2.22 & & -2.84 & & -2.13 & & -2.21 & & 92 \\
\hline Zapatos para mujer & -1.21 & & 0.11 & & -1.50 & & -2.29 & & -1.15 & & 92 \\
\hline Zapatos para niño & 1.04 & & 2.51 & & -1.87 & & -0.50 & & 0.82 & & 92 \\
\hline Tenis & 1.32 & & 1.73 & & 1.97 & & 2.85 & & 2.45 & & 92 \\
\hline Otro tipo de calzado: huaraches, sandalias, etc. & 0.17 & & 0.96 & & -2.26 & & 0.44 & & -1.99 & & 92 \\
\hline Servicio de limpieza y reparación de calzado & -2.45 & & 0.04 & & -1.71 & & -2.19 & & 0.37 & & 92 \\
\hline Sombreros, gorros y cachuchas & 0.29 & & -6.61 & $* *$ & -1.69 & & -1.49 & & -3.89 & & 92 \\
\hline Bolsas, portafolios y cinturones & -3.74 & & -0.47 & & 0.54 & & -0.48 & & 3.44 & & 92 \\
\hline Joyería y joyería de fantasía & 0.08 & & 0.05 & & -0.04 & & 0.29 & & 0.07 & & 92 \\
\hline Relojes & 1.18 & & -1.82 & & -1.91 & & -1.15 & & -1.34 & & 92 \\
\hline
\end{tabular}


Cuadro A1 (continuación)

\begin{tabular}{|c|c|c|c|c|c|c|c|c|c|c|}
\hline & Marzo & & Abril & & Mayo & & Junio & & Julio & \\
\hline \multicolumn{11}{|l|}{ Cristalería, blancos y utensilios domésticos } \\
\hline Vajilla y piezas de cristal o barro & -0.76 & & 3.57 & & 1.70 & & -1.02 & & 0.98 & \\
\hline Artículos de plástico & 4.14 & & 9.66 & $* * *$ & -1.11 & & -1.46 & & 4.40 & \\
\hline Baterías de cocina & 4.88 & $* * *$ & 1.47 & & -3.67 & & -1.93 & & -1.27 & \\
\hline Otros utensilios de cocina & -4.73 & & 2.11 & & 5.51 & & 3.48 & & 3.11 & \\
\hline Colchones & 0.03 & & -0.81 & & -4.94 & & -0.62 & & 0.02 & \\
\hline Cobertores y cobijas & 0.50 & & 1.79 & & -0.57 & & 0.61 & & -0.97 & \\
\hline Sábanas & 0.76 & & 2.01 & & 2.53 & & -3.00 & & 3.22 & \\
\hline Colchas & 1.76 & & -3.24 & & -2.51 & & -4.05 & & 0.43 & \\
\hline Toallas & 2.71 & & 1.20 & & -7.62 & $* *$ & -10.61 & $* *$ & -1.34 & \\
\hline Cortinas & -6.44 & & 5.44 & & 1.49 & & 4.66 & & 4.47 & \\
\hline Hilos, hilazas y estambres & 8.49 & & 0.48 & & -2.96 & & -1.06 & & -3.51 & \\
\hline Otros blancos para el hogar & -0.45 & & 1.15 & & -4.17 & & 0.08 & & 1.40 & \\
\hline \multicolumn{11}{|l|}{ Cuidados de la Salud } \\
\hline Análisis médicos & 1.84 & & 2.59 & & -1.39 & & -1.77 & & -1.85 & \\
\hline Hospitalización & 7.07 & $* *$ & 0.69 & & -1.68 & & -5.60 & & -11.64 & $* *$ \\
\hline Ambulancia y material de cirugía & 1.46 & & 4.09 & & 0.55 & & -0.17 & & 0.03 & \\
\hline Anteojos y otros aparatos & -10.28 & $* * *$ & 10.08 & & 5.35 & & 8.32 & $* *$ & 7.06 & \\
\hline \multicolumn{11}{|c|}{ Enseres domésticos y mantenimiento de la vivienda } \\
\hline Ventiladores & -6.99 & & 8.98 & $* * *$ & 1.76 & & 2.70 & & 5.76 & \\
\hline Servicio doméstico & 1.97 & & 2.75 & & -1.80 & & 0.96 & & 0.86 & \\
\hline Máquinas de cocer & -0.83 & & 0.73 & & -5.30 & $* * *$ & -3.65 & & -4.54 & \\
\hline Estufas de gas & -1.95 & & 4.23 & & 3.90 & & 0.94 & & 3.45 & \\
\hline Refrigeradores & -0.93 & & 2.06 & & -3.65 & & -0.28 & & -2.00 & \\
\hline Licuadoras & 1.01 & & 2.20 & & -4.74 & $* * *$ & -3.78 & & -3.28 & \\
\hline Plancha & 1.04 & & -3.20 & & -0.88 & & -5.41 & & -5.47 & \\
\hline Lavadoras & -0.82 & & 2.42 & & -0.16 & & 1.92 & & -0.81 & \\
\hline Calentadores de agua & -3.54 & & 8.55 & $* *$ & 12.09 & $* *$ & -0.13 & & 1.39 & \\
\hline Otros enseres eléctricos & 1.71 & & 2.69 & & -0.24 & & 2.82 & & 0.69 & \\
\hline Juego de recámara & -5.37 & & 2.43 & & 0.90 & & 0.82 & & -7.54 & $* *$ \\
\hline Juego de comedor o antecomedor & 5.02 & & 0.62 & & -0.16 & & -5.65 & & -1.17 & \\
\hline Piezas sueltas para comedor & 2.34 & & -0.96 & & -4.06 & & -4.45 & & -1.84 & \\
\hline Juego de sala & 0.65 & & 2.35 & & -2.53 & & -2.95 & & -3.74 & \\
\hline Muebles para cocina (gabinetes, etc.) & -1.04 & & 2.04 & & -3.30 & & -0.57 & & 0.18 & \\
\hline \multicolumn{11}{|l|}{ Artículos de esparcimiento } \\
\hline Radios y grabadoras & -1.49 & & 1.64 & & -1.21 & & 0.38 & & -1.91 & \\
\hline Estéreo y modular & 2.91 & & 0.62 & & -1.60 & & -2.18 & & -7.87 & $* * *$ \\
\hline Televisores y videocasseteras & 1.40 & & 2.73 & & 2.96 & & 1.64 & & 0.55 & \\
\hline Equipo fotográfico & 7.27 & $* *$ & 4.66 & & -2.51 & & -4.65 & & -0.37 & \\
\hline Juguetes & -7.22 & & 3.34 & & 3.81 & & -0.72 & & 2.32 & \\
\hline Instrumentos musciales & 4.49 & & 1.46 & & -3.32 & & -1.13 & & -1.65 & \\
\hline Artículos de deporte y cacería & 1.41 & & 0.20 & & -6.76 & $* *$ & -7.13 & $* *$ & -3.40 & \\
\hline \multicolumn{11}{|l|}{ Transporte } \\
\hline Transporte ferroaviario & -0.43 & & -0.57 & & 0.81 & & -1.14 & & -0.94 & \\
\hline Transporte aéreo & 3.97 & & 0.65 & & -1.85 & & -2.85 & & 0.41 & \\
\hline Cuotas de autopista & 0.07 & & 5.37 & $* * *$ & -0.01 & & -0.48 & & 1.53 & \\
\hline Automóvil & 0.13 & & 1.56 & & -1.86 & & 0.42 & & 0.51 & \\
\hline Bicicletas & 1.03 & & 5.59 & & -2.72 & & 0.49 & & -1.55 & \\
\hline Llantas & 0.21 & & 6.36 & & 2.48 & & 2.83 & & -0.30 & \\
\hline Acumulador & -3.27 & & -1.17 & & 0.75 & & -2.69 & & -5.63 & $* *$ \\
\hline Refacciones & 14.68 & $* *$ & 6.07 & & -0.86 & & -2.21 & & -4.61 & \\
\hline Servicio de afinación, alineación y balanceo & -3.07 & & 6.07 & & 2.54 & & 2.21 & & 0.34 & \\
\hline \multicolumn{11}{|l|}{ Otros gastos } \\
\hline Funerales, cementerios & 2.89 & & -1.18 & & -9.38 & $* * *$ & -10.55 & $* *$ & -6.12 & \\
\hline Impuesto sobre tenencia & -0.04 & & 1.16 & & 0.51 & & 0.13 & & 0.13 & \\
\hline Seguro de automóvil & -0.06 & & 0.20 & & 0.69 & $*$ & 0.36 & $* *$ & 1.21 & $*$ \\
\hline Trámites para vehículos: licencias, placas, etc. & -0.70 & & -1.18 & & -5.69 & $* *$ & -4.52 & $* *$ & -2.08 & \\
\hline
\end{tabular}




\section{Cuadro A1 (continuación)}

\begin{tabular}{|c|c|c|c|c|c|c|c|c|c|}
\hline & \multicolumn{2}{|c|}{ Agosto } & \multicolumn{2}{|c|}{ Septiembre } & \multicolumn{2}{|c|}{ Octubre } & Noviembre & Diciembre & \multirow[t]{2}{*}{ Muestra } \\
\hline \multicolumn{9}{|l|}{ Cristalería, blancos y utensilios domésticos } & \\
\hline Vajilla y piezas de cristal o barro & 1.01 & & -1.15 & & -0.61 & & -0.18 & 1.07 & 92 \\
\hline Artículos de plástico & 5.68 & & 2.76 & & 3.67 & & 2.87 & 3.66 & 92 \\
\hline Baterías de cocina & -0.40 & & -3.52 & & -2.01 & & -3.22 & -3.32 & 92 \\
\hline Otros utensilios de cocina & 4.40 & & 4.71 & & 4.75 & & 2.97 & 2.57 & 92 \\
\hline Colchones & 0.80 & & 0.52 & & -0.27 & & 0.25 & 0.18 & 92 \\
\hline Cobertores y cobijas & -0.85 & & -4.69 & & -8.49 & $* *$ & $-8.77 * *$ & -1.54 & 92 \\
\hline Sábanas & 2.51 & & -1.67 & & -5.96 & $* *$ & -0.04 & -1.62 & 92 \\
\hline Colchas & -0.96 & & 0.04 & & 0.08 & & 0.33 & -1.23 & 92 \\
\hline Toallas & -2.01 & & -5.40 & & -9.86 & $* *$ & -3.15 & -0.40 & 92 \\
\hline Cortinas & 1.56 & & 2.21 & & 1.61 & & 0.64 & 2.52 & 92 \\
\hline Hilos, hilazas y estambres & -3.51 & & -4.33 & & -2.04 & & -0.67 & -3.73 & 92 \\
\hline Otros blancos para el hogar & -3.00 & & 0.20 & & 0.36 & & 2.97 & -0.84 & 92 \\
\hline \multicolumn{10}{|l|}{ Cuidados de la Salud } \\
\hline Análisis médicos & -1.79 & & -3.16 & & -3.52 & & -0.39 & -2.52 & 92 \\
\hline Hospitalización & -4.39 & $* * *$ & -3.09 & $* * *$ & -3.76 & $* * *$ & -1.29 & -4.33 & 92 \\
\hline Ambulancia y material de cirugía & 1.09 & & -0.83 & & -1.81 & & -0.23 & 0.50 & 92 \\
\hline Anteojos y otros aparatos & 5.95 & & 8.14 & $* * *$ & 7.72 & & 8.57 & $7.89 * *$ & 92 \\
\hline \multicolumn{10}{|c|}{ Enseres domésticos y mantenimiento de la vivienda } \\
\hline Ventiladores & 6.72 & $* *$ & 8.14 & $* *$ & 7.21 & $* *$ & $6.90 * *$ & 3.54 & 92 \\
\hline Servicio doméstico & 0.98 & & -0.56 & & -2.13 & & -0.17 & 2.02 & 92 \\
\hline Máquinas de cocer & -4.42 & & -2.08 & & -2.54 & & -3.49 & -1.40 & 92 \\
\hline Estufas de gas & 3.83 & & 2.98 & & 0.27 & & 1.30 & 6.61 & 92 \\
\hline Refrigeradores & -1.25 & & -3.08 & $* * *$ & -4.38 & $* *$ & -2.90 & -0.46 & 92 \\
\hline Licuadoras & -0.73 & & -1.50 & & -1.95 & & $-4.07 * *$ & -3.36 & 92 \\
\hline Plancha & -4.03 & & -1.32 & & -1.10 & & 0.22 & -1.67 & 92 \\
\hline Lavadoras & -0.05 & & 0.57 & & -0.27 & & -2.48 & 1.87 & 92 \\
\hline Calentadores de agua & -1.29 & & 3.23 & & 3.57 & & 4.29 & -0.10 & 92 \\
\hline Otros enseres eléctricos & -2.04 & & -3.00 & & 0.00 & & 0.44 & -1.38 & 92 \\
\hline Juego de recámara & -0.82 & & -2.04 & & -1.26 & & -1.15 & -0.06 & 92 \\
\hline Juego de comedor o antecomedor & -3.61 & & -3.21 & & -1.12 & & -0.39 & -3.29 & 92 \\
\hline Piezas sueltas para comedor & -3.34 & & -4.73 & & -1.58 & & -1.78 & -2.80 & 92 \\
\hline Juego de sala & -3.61 & & -2.35 & & -3.89 & & -2.86 & -0.94 & 92 \\
\hline Muebles para cocina (gabinetes, etc.) & -1.22 & & -2.31 & & -0.19 & & 0.09 & 0.65 & 92 \\
\hline \multicolumn{10}{|l|}{ Artículos de esparcimiento } \\
\hline Radios y grabadoras & 0.62 & & -1.82 & & -3.38 & & -3.09 & -3.33 & 92 \\
\hline Estéreo y modular & -3.51 & & -3.12 & & -4.59 & & -5.78 & -4.44 & 92 \\
\hline Televisores y videocasseteras & 0.48 & & 0.55 & & -0.09 & & -0.48 & -1.85 & 92 \\
\hline Equipo fotográfico & -1.82 & & -2.10 & & -0.68 & & $-6.12 * *$ & -3.59 & 92 \\
\hline Juguetes & 4.93 & $* * *$ & -0.03 & & -0.27 & & 3.78 & 4.65 & 92 \\
\hline Instrumentos musciales & -5.22 & & -4.32 & & -3.15 & & -0.83 & -4.64 & 92 \\
\hline Artículos de deporte y cacería & -0.37 & & -0.58 & & -4.31 & $* *$ & -3.15 & $-4.01 * * *$ & 92 \\
\hline \multicolumn{10}{|l|}{ Transporte } \\
\hline Transporte ferroaviario & -1.12 & & -1.08 & & -4.67 & $* *$ & -0.42 & -1.52 & 90 \\
\hline Transporte aéreo & -1.32 & & 0.65 & & 1.06 & & -3.04 & -2.10 & 88 \\
\hline Cuotas de autopista & 0.80 & & 0.56 & & 0.15 & & -0.08 & -0.90 & 92 \\
\hline Automóvil & -0.53 & & -0.47 & & 1.30 & & -0.07 & 0.38 & 92 \\
\hline Bicicletas & -1.67 & & -2.62 & & 1.52 & & 1.13 & 3.68 & 92 \\
\hline Llantas & 1.82 & & 1.93 & & 3.31 & & 0.91 & 0.45 & 92 \\
\hline Acumulador & -0.82 & & -1.28 & & 0.39 & & -0.06 & -1.87 & 92 \\
\hline Refacciones & -0.47 & & -1.35 & & -1.37 & & 1.20 & -0.45 & 92 \\
\hline Servicio de afinación, alineación y balanceo & 3.39 & & 0.31 & & 2.77 & & 3.23 & -2.29 & 92 \\
\hline \multicolumn{10}{|l|}{ Otros gastos } \\
\hline Funerales, cementerios & -7.03 & & -7.35 & & -10.28 & $* *$ & -4.65 & -4.43 & 92 \\
\hline Impuesto sobre tenencia & 0.13 & & 0.13 & & 0.13 & & 0.30 & 0.44 & 92 \\
\hline Seguro de automóvil & 1.62 & $*$ & 2.13 & $*$ & 0.78 & $*$ & 0.20 & 0.02 & 92 \\
\hline Trámites para vehículos: licencias, placas, etc. & -1.46 & & -2.45 & & -2.51 & & -1.35 & -2.60 & 92 \\
\hline
\end{tabular}

(* significativo al $1 \%, * *$ al $5 \%, * * *$ al $10 \%)$ 


\section{Apéndice 3. Incidencia del IVA por Producto}

Cuadro A2. Incidencia del IVA

\begin{tabular}{|c|c|c|c|c|}
\hline & \multicolumn{2}{|c|}{$\begin{array}{c}\text { Cambio en el Precio } \\
\text { (Unidades del Índice de } \\
\text { Precios) }\end{array}$} & \multicolumn{2}{|c|}{$\begin{array}{c}\text { Incidencia del Impuesto } \\
\text { (Porcentaje) }\end{array}$} \\
\hline & Consumidor & Productor & Consumidor & Productor \\
\hline \multicolumn{5}{|l|}{ Alimentos, bebidas y tabaco } \\
\hline Carnitas de Puerco & 0.00 & -4.07 & 0.00 & 100.00 \\
\hline Pollo Rostizado & 5.65 & 0.52 & 110.07 & -10.07 \\
\hline Barbacoa de Borrego & 0.00 & -4.49 & 0.00 & 100.00 \\
\hline Otros alimentos preparados & 0.00 & -4.51 & 0.00 & 100.00 \\
\hline Refrescos embotellados & 0.00 & -4.75 & 0.00 & 100.00 \\
\hline Jugos o néctares enlatados & 0.00 & -4.73 & 0.00 & 100.00 \\
\hline Concentrado y polvo para preparar agua & 0.00 & -4.79 & 0.00 & 100.00 \\
\hline Cerveza & 0.00 & -4.40 & 0.00 & 100.00 \\
\hline Brandy & 4.83 & -0.42 & 91.96 & 8.04 \\
\hline Tequila & 4.21 & -0.87 & 82.82 & 17.18 \\
\hline Ron & 0.00 & -4.59 & 0.00 & 100.00 \\
\hline Vinos de mesa & 0.00 & -4.56 & 0.00 & 100.00 \\
\hline Otros licores & 20.57 & 13.25 & 281.07 & -181.07 \\
\hline Cigarros & 6.31 & 0.77 & 113.95 & -13.95 \\
\hline \multicolumn{5}{|l|}{ Transporte público } \\
\hline Metro & 0.00 & 0.00 & N.A. & N.A. \\
\hline Autobús & 41.78 & 30.67 & 375.96 & -275.96 \\
\hline Colectivo(pesero) & 0.00 & -5.06 & 0.00 & 100.00 \\
\hline Taxi, radio taxi (sitio) & 0.00 & -4.52 & 0.00 & 100.00 \\
\hline Autobús foráneo & -17.34 & -19.99 & -652.27 & 752.27 \\
\hline \multicolumn{5}{|l|}{ Limpieza y cuidado de la casa } \\
\hline Detergentes y similares & 0.00 & -4.82 & 0.00 & 100.00 \\
\hline Jabón de barra & 0.00 & -5.37 & 0.00 & 100.00 \\
\hline Blanqueadores y limpiadores & 6.05 & 0.46 & 108.21 & -8.21 \\
\hline Papel sanitario & 0.00 & -4.81 & 0.00 & 100.00 \\
\hline Servilletas y papel absorbente & 0.00 & -4.66 & 0.00 & 100.00 \\
\hline Escobas y trapeadores & -9.35 & -12.80 & -271.28 & 371.28 \\
\hline Cerillos & -16.08 & -18.92 & -565.23 & 665.23 \\
\hline Pilas & 20.89 & 13.08 & 267.51 & -167.51 \\
\hline Focos & 11.95 & 5.61 & 188.50 & -88.50 \\
\hline Insecticidas & 0.00 & -4.66 & 0.00 & 100.00 \\
\hline Desodorante ambiental y sanitario & -8.87 & -12.41 & -250.38 & 350.38 \\
\hline Tintorería & 0.00 & -4.35 & 0.00 & 100.00 \\
\hline
\end{tabular}




\begin{tabular}{|c|c|c|c|c|}
\hline & \multicolumn{2}{|c|}{$\begin{array}{c}\text { Cambio en el Precio } \\
\text { (Unidades del Îndice de } \\
\text { Precios) }\end{array}$} & \multicolumn{2}{|c|}{$\begin{array}{l}\text { Incidencia del Impuesto } \\
\text { (Porcentaje) }\end{array}$} \\
\hline & Consumidor & Productor & Consumidor & Productor \\
\hline \multicolumn{5}{|l|}{ Cuidados Personales } \\
\hline Jabón de tocador & 21.69 & 13.67 & 270.39 & -170.39 \\
\hline Lociones y perfumes & 0.00 & -5.29 & 0.00 & 100.00 \\
\hline Pasta dental y enjuague bucal & 0.00 & -5.00 & 0.00 & 100.00 \\
\hline Shampoos, tintes y enjuagues & -7.87 & -11.22 & -235.03 & 335.03 \\
\hline Desodorante & -8.54 & -12.13 & -238.06 & 338.06 \\
\hline Crema, brillantina y crema para afeitar & 0.00 & -4.97 & 0.00 & 100.00 \\
\hline Navajas y rastrillos para afeitar & 0.00 & -4.61 & 0.00 & 100.00 \\
\hline Polvo y maquillaje facial & 0.00 & -4.82 & 0.00 & 100.00 \\
\hline Pañuelos desechables & 8.98 & 3.31 & 158.38 & -58.38 \\
\hline Pañales desechables & 0.00 & -5.16 & 0.00 & 100.00 \\
\hline Toallas sanitarias & 0.00 & -5.05 & 0.00 & 100.00 \\
\hline $\begin{array}{l}\text { Otros: esmaltes y limas para uñas, pasadores, } \\
\text { etc. }\end{array}$ & 0.00 & -4.68 & 0.00 & 100.00 \\
\hline Corte de cabello y peinado & 0.00 & -4.11 & 0.00 & 100.00 \\
\hline Baños y masajes & 39.29 & 29.09 & 385.45 & -285.45 \\
\hline Salón de belleza & 0.00 & -4.14 & 0.00 & 100.00 \\
\hline \multicolumn{5}{|l|}{ Educación, cultura y recreación } \\
\hline Estudios técnicos y de lenguas & 0.00 & -4.14 & 0.00 & 100.00 \\
\hline Libros para la escuela & 0.00 & -4.30 & 0.00 & 100.00 \\
\hline Cuadernos, carpetas, etc. & 13.09 & 6.62 & 202.27 & -102.27 \\
\hline Lápices, plumas, etc. & 14.47 & 7.07 & 195.61 & -95.61 \\
\hline Periódicos y revistas & 0.00 & -5.56 & 0.00 & 100.00 \\
\hline Revistas & 0.00 & -5.07 & 0.00 & 100.00 \\
\hline Audio cassetes, discos y discos compactos & 0.00 & -4.79 & 0.00 & 100.00 \\
\hline Otros libros & 0.00 & -4.41 & 0.00 & 100.00 \\
\hline Cines & 0.00 & -4.94 & 0.00 & 100.00 \\
\hline Centros nocturnos & 0.00 & -4.72 & 0.00 & 100.00 \\
\hline Hoteles & 2.94 & -1.69 & 63.57 & 36.43 \\
\hline Clubes deportivos & 0.00 & -4.95 & 0.00 & 100.00 \\
\hline Otros gastos de recreación: circos, museos, etc. & 0.00 & -4.55 & 0.00 & 100.00 \\
\hline Restaurantes, cantinas y similares & 0.00 & -4.51 & 0.00 & 100.00 \\
\hline Almuerzos & -10.22 & -13.49 & -313.25 & 413.25 \\
\hline Cafeterías & 0.00 & -4.88 & 0.00 & 100.00 \\
\hline Cantinas & 0.00 & -4.85 & 0.00 & 100.00 \\
\hline \multicolumn{5}{|l|}{ Comunicaciones y servicios para vehículos } \\
\hline Teléfono particular & 4.62 & -0.07 & 98.55 & 1.45 \\
\hline Servicio telefónico local & 0.00 & -4.59 & 0.00 & 100.00 \\
\hline Larga distancia nacional & 0.00 & -4.35 & 0.00 & 100.00 \\
\hline Larga distancia internacional & 0.00 & -5.06 & 0.00 & 100.00 \\
\hline Gasolina, diesel o gas & 4.39 & -2.03 & 68.43 & 31.57 \\
\hline Aceites y lubricantes & -11.39 & -15.45 & -280.63 & 380.63 \\
\hline Pensión y estacionamiento & 0.00 & -4.69 & 0.00 & 100.00 \\
\hline \multicolumn{5}{|l|}{ Vivienda y servicios de conservación } \\
\hline Vivienda propia & 1.56 & -3.35 & 31.77 & 68.23 \\
\hline Mantenimiento y servicios de conservación & 0.00 & -4.94 & 0.00 & 100.00 \\
\hline Vivienda rentada o alquilada & 0.00 & -4.71 & 0.00 & 100.00 \\
\hline Energía eléctrica & 9.21 & 3.51 & 161.55 & -61.55 \\
\hline Gas doméstico & 8.13 & 2.53 & 145.20 & -45.20 \\
\hline Velas y veladoras & 0.00 & -4.66 & 0.00 & 100.00 \\
\hline Otros combustibles: cartón, papel, etc. & 22.15 & 13.86 & 267.29 & -167.29 \\
\hline
\end{tabular}




\begin{tabular}{|c|c|c|c|c|}
\hline & \multicolumn{2}{|c|}{$\begin{array}{c}\text { Cambio en el Precio } \\
\text { (Unidades del Índice de Precios) }\end{array}$} & \multicolumn{2}{|c|}{$\begin{array}{c}\text { Incidencia del Impuesto } \\
\text { (Porcentaje) }\end{array}$} \\
\hline & Consumidor & Productor & Consumidor & Productor \\
\hline \multicolumn{5}{|l|}{ Prendas de vestir, calzado y accesorios } \\
\hline Pantalones para hombre de mezclilla & 11.97 & 5.82 & 194.77 & -94.77 \\
\hline Pantalones para hombre de fibras sintéticas & 7.00 & 1.12 & 119.04 & -19.04 \\
\hline Pantalones para mujer de mezclilla & 0.00 & -4.25 & 0.00 & 100.00 \\
\hline Pantalones para mujer de fibras sintéticas & -5.23 & -8.72 & -150.05 & 250.05 \\
\hline Chamarras y chaquetas & 6.08 & 0.86 & 116.50 & -16.50 \\
\hline Blusas y playeras para mujer & -6.44 & -9.82 & -190.46 & 290.46 \\
\hline Trajes & 0.00 & -4.73 & 0.00 & 100.00 \\
\hline Vestidos & 0.00 & -4.23 & 0.00 & 100.00 \\
\hline Conjuntos para mujer & 0.00 & -3.69 & 0.00 & 100.00 \\
\hline Faldas & 4.92 & 0.11 & 102.18 & -2.18 \\
\hline Abrigos & 0.00 & -3.38 & 0.00 & 100.00 \\
\hline Suéteres & 14.39 & 7.39 & 205.40 & -105.40 \\
\hline Calzoncillos y truzas & 17.12 & 9.93 & 237.97 & -137.97 \\
\hline Camisetas y playeras & 0.00 & -5.32 & 0.00 & 100.00 \\
\hline Calcetines & 0.00 & -4.53 & 0.00 & 100.00 \\
\hline Calcetas y mallas & 12.09 & 4.96 & 169.48 & -69.48 \\
\hline Pantaletas & 0.00 & -4.47 & 0.00 & 100.00 \\
\hline Medias, pantimedias y tobimedias & 0.00 & -4.29 & 0.00 & 100.00 \\
\hline Calzoncillos para niño & 0.00 & -4.49 & 0.00 & 100.00 \\
\hline Vestidos para niña & 5.89 & 0.76 & 114.86 & -14.86 \\
\hline Pantaletas para niña & 0.00 & -4.50 & 0.00 & 100.00 \\
\hline Pijamas y batas & 0.00 & -4.29 & 0.00 & 100.00 \\
\hline Otras prendas para hombre (corbatas, etc.) & 8.09 & 2.75 & 151.45 & -51.45 \\
\hline Otras prendas de vestir & 0.00 & -4.08 & 0.00 & 100.00 \\
\hline Pantalones de niño de fibras sintéticas & 8.36 & 3.07 & 158.06 & -58.06 \\
\hline Pantalones de niño de algodón & 0.00 & -4.48 & 0.00 & 100.00 \\
\hline Blusas para niño & 14.79 & 8.24 & 225.79 & -125.79 \\
\hline Playeras para bebé & 0.00 & -4.25 & 0.00 & 100.00 \\
\hline Suéter para niño & 0.00 & -4.20 & 0.00 & 100.00 \\
\hline Suéter para niña & 0.00 & -4.40 & 0.00 & 100.00 \\
\hline Uniformes escolares para niño & 0.00 & -4.43 & 0.00 & 100.00 \\
\hline Uniformes escolares para niña & 0.00 & -4.31 & 0.00 & 100.00 \\
\hline Zapatos para hombre & 0.00 & -4.19 & 0.00 & 100.00 \\
\hline Zapatos para mujer & 4.46 & -0.41 & 91.56 & 8.44 \\
\hline Zapatos para niño & 6.01 & 0.96 & 119.04 & -19.04 \\
\hline Tenis & 8.19 & 2.56 & 145.53 & -45.53 \\
\hline Otro tipo de calzado: huaraches, sandalias, etc. & 0.00 & -4.43 & 0.00 & 100.00 \\
\hline Servicio de limpieza y reparación de calzado & 0.00 & -4.31 & 0.00 & 100.00 \\
\hline Sombreros, gorros y cachuchas & 0.00 & -4.65 & 0.00 & 100.00 \\
\hline Bolsas, portafolios y cinturones & 0.00 & -4.36 & 0.00 & 100.00 \\
\hline Joyería y joyería de fantasía & 0.00 & -7.41 & 0.00 & 100.00 \\
\hline Relojes & 0.00 & -4.83 & 0.00 & 100.00 \\
\hline
\end{tabular}




\begin{tabular}{|c|c|c|c|c|}
\hline & \multicolumn{2}{|c|}{$\begin{array}{c}\text { Cambio en el Precio } \\
\text { (Unidades del Índice de } \\
\text { Precios) }\end{array}$} & \multicolumn{2}{|c|}{$\begin{array}{c}\text { Incidencia del Impuesto } \\
\text { (Porcentaje) }\end{array}$} \\
\hline & Consumidor & Productor & Consumidor & Productor \\
\hline \multicolumn{5}{|l|}{ Cristalería, blancos y utensilios domésticos } \\
\hline Vajilla y piezas de cristal o barro & 0.00 & -4.48 & 0.00 & 100.00 \\
\hline Artículos de plástico & 12.61 & 5.81 & 185.32 & -85.32 \\
\hline Baterías de cocina & 0.00 & -4.59 & 0.00 & 100.00 \\
\hline Otros utensilios de cocina & 0.00 & -4.73 & 0.00 & 100.00 \\
\hline Colchones & 0.00 & -4.58 & 0.00 & 100.00 \\
\hline Cobertores y cobijas & 0.00 & -4.24 & 0.00 & 100.00 \\
\hline Sábanas & 0.00 & -4.33 & 0.00 & 100.00 \\
\hline Colchas & 0.00 & -4.39 & 0.00 & 100.00 \\
\hline Toallas & -8.12 & -11.27 & -257.55 & 357.55 \\
\hline Cortinas & 0.00 & -4.44 & 0.00 & 100.00 \\
\hline Hilos, hilazas y estambres & 0.00 & -4.75 & 0.00 & 100.00 \\
\hline Otros blancos para el hogar & 0.00 & -4.57 & 0.00 & 100.00 \\
\hline \multicolumn{5}{|l|}{ Cuidados de la Salud } \\
\hline Análisis médicos & 0.00 & -4.80 & 0.00 & 100.00 \\
\hline Hospitalización & 0.00 & -4.56 & 0.00 & 100.00 \\
\hline Ambulancia y material de cirugía & 0.00 & -4.84 & 0.00 & 100.00 \\
\hline Anteojos y otros aparatos & 0.00 & -4.79 & 0.00 & 100.00 \\
\hline \multicolumn{5}{|l|}{$\begin{array}{l}\text { Enseres domésticos y mantenimiento de la } \\
\text { vivienda }\end{array}$} \\
\hline Ventiladores & 10.45 & 4.49 & 175.26 & -75.26 \\
\hline Servicio doméstico & 0.00 & -4.38 & 0.00 & 100.00 \\
\hline Máquinas de cocer & -6.19 & -10.00 & -162.51 & 262.51 \\
\hline Estufas de gas & 0.00 & -5.20 & 0.00 & 100.00 \\
\hline Refrigeradores & 0.00 & -4.48 & 0.00 & 100.00 \\
\hline Licuadoras & -5.24 & -8.92 & -142.16 & 242.16 \\
\hline Plancha & 0.00 & -4.66 & 0.00 & 100.00 \\
\hline Lavadoras & 0.00 & -4.54 & 0.00 & 100.00 \\
\hline Calentadores de agua & 25.50 & 17.29 & 310.62 & -210.62 \\
\hline Otros enseres eléctricos & 0.00 & -4.85 & 0.00 & 100.00 \\
\hline Juego de recámara & 0.00 & -4.17 & 0.00 & 100.00 \\
\hline Juego de comedor o ante comedor & 0.00 & -4.96 & 0.00 & 100.00 \\
\hline Piezas sueltas para comedor & 0.00 & -4.66 & 0.00 & 100.00 \\
\hline Juego de sala & 0.00 & -4.43 & 0.00 & 100.00 \\
\hline Muebles para cocina (gabinetes, etc.) & 0.00 & -4.51 & 0.00 & 100.00 \\
\hline \multicolumn{5}{|l|}{ Artículos de esparcimiento } \\
\hline Radios y grabadoras & 0.00 & -4.68 & 0.00 & 100.00 \\
\hline Estéreo y modular & 0.00 & -4.66 & 0.00 & 100.00 \\
\hline Televisores y video caseteras & 0.00 & -5.18 & 0.00 & 100.00 \\
\hline Equipo fotográfico & 0.00 & -4.82 & 0.00 & 100.00 \\
\hline Juguetes & 0.00 & -4.32 & 0.00 & 100.00 \\
\hline Instrumentos musicales & 0.00 & -4.52 & 0.00 & 100.00 \\
\hline Artículos de deporte y cacería & -7.81 & -11.36 & -220.14 & 320.14 \\
\hline
\end{tabular}




\begin{tabular}{lcccc}
\hline \hline & \multicolumn{2}{c}{$\begin{array}{c}\text { Cambio en el Precio } \\
\text { (Unidades del Índice de } \\
\text { Precios) }\end{array}$} & \multicolumn{2}{c}{$\begin{array}{c}\text { Incidencia del Impuesto } \\
\text { (Porcentaje) }\end{array}$} \\
& $\begin{array}{c}\text { Consumidor } \\
\text { Productor }\end{array}$ & Consumidor & Productor \\
\hline Transporte & & & & \\
$\quad$ Transporte ferroviario & 0.00 & -4.43 & 0.00 & 100.00 \\
$\quad$ Transporte aéreo & 0.00 & -4.96 & 0.00 & 100.00 \\
Cuotas de autopista & 5.48 & 0.73 & 115.41 & -15.41 \\
$\quad$ Automóvil & 0.00 & -4.86 & 0.00 & 100.00 \\
Bicicletas & 0.00 & -4.62 & 0.00 & 100.00 \\
$\quad$ Llantas & 0.00 & -5.23 & 0.00 & 100.00 \\
$\quad$ Acumulador & 0.00 & -4.58 & 0.00 & 100.00 \\
$\quad$ Refacciones & 0.00 & -5.53 & 0.00 & 100.00 \\
$\quad$ Servicio de afinación, alineación y balanceo & 0.00 & -4.71 & 0.00 & 100.00 \\
Otros gastos & -9.99 & -12.90 & -343.70 & 443.70 \\
$\quad$ Funerales, cementerios & -4.00 & -4.49 & 0.00 & 100.00 \\
$\quad$ Impuesto sobre tenencia & 0.77 & -3.76 & 17.07 & 82.93 \\
$\quad$ Seguro de automóvil & -6.78 & -10.60 & -177.24 & 277.24 \\
$\quad$ Trámites para vehículos: licencias, placas, etc. & & & & \\
\hline \hline
\end{tabular}


Apéndice 4. Elasticidades de Demanda y Oferta Relativas Cuadro A3. Categorías de Gasto: Factor de Elasticidades Relativas

\begin{tabular}{|c|c|}
\hline & Factor \\
\hline \multicolumn{2}{|l|}{ Alimentos, bebidas y tabaco } \\
\hline Carnitas de Puerco & N.A. \\
\hline Pollo Rostizado & 0.22 \\
\hline Barbacoa de Borrego & N.A. \\
\hline Otros alimentos preparados & N.A. \\
\hline Refrescos embotellados & N.A. \\
\hline Jugos o néctares enlatados & N.A. \\
\hline Concentrado y polvo para preparar agua & N.A. \\
\hline Cerveza & N.A. \\
\hline Brandy & 0.25 \\
\hline Tequila & 0.28 \\
\hline Ron & N.A. \\
\hline Vinos de mesa & N.A. \\
\hline Otros licores & 0.06 \\
\hline Cigarros & 0.19 \\
\hline \multicolumn{2}{|l|}{ Transporte público } \\
\hline Metro & N.A. \\
\hline Autobús & 0.03 \\
\hline Colectivo(pesero) & N.A. \\
\hline Taxi, radio taxi (sitio) & N.A. \\
\hline Autobús foráneo & -0.07 \\
\hline \multicolumn{2}{|l|}{ Limpieza y cuidado de la casa } \\
\hline Detergentes y similares & N.A. \\
\hline Jabón de barra & N.A. \\
\hline Blanqueadores y limpiadores & 0.19 \\
\hline Papel sanitario & N.A. \\
\hline Servilletas y papel absorbente & N.A. \\
\hline Escobas y trapeadores & -0.11 \\
\hline Cerillos & -0.07 \\
\hline Pilas & 0.05 \\
\hline Focos & 0.09 \\
\hline Insecticidas & N.A. \\
\hline Desodorante ambiental y sanitario & -0.12 \\
\hline Tintorería & N.A. \\
\hline \multicolumn{2}{|l|}{ Cuidados Personales } \\
\hline Jabón de tocador & 0.05 \\
\hline Lociones y perfumes & N.A. \\
\hline Pasta dental y enjuague bucal & N.A. \\
\hline Shampoos, tintes y enjuagues & -0.12 \\
\hline Desodorante & -0.12 \\
\hline Crema, brillantina y crema para afeitar & N.A. \\
\hline Navajas y rastrillos para afeitar & N.A. \\
\hline Polvo y maquillaje facial & N.A. \\
\hline Pañuelos desechables & 0.10 \\
\hline Pañales desechables & N.A. \\
\hline Toallas sanitarias & N.A. \\
\hline Otros: esmaltes y limas para uñas, pasadores, etc. & N.A. \\
\hline Corte de cabello y peinado & N.A. \\
\hline Baños y masajes & 0.03 \\
\hline Salón de belleza & N.A. \\
\hline
\end{tabular}




\section{Educación, cultura y recreación}

Estudios técnicos y de lenguas N.A.

Libros para la escuela N.A.

Cuadernos, carpetas, etc. $\quad 0.07$

Lápices, plumas, etc. $\quad 0.07$

Periódicos y revistas N.A.

Revistas N.A.

Audio cassetes, discos y discos compactos N.A.

Otros libros N.A.

Cines N.A.

Centros nocturnos N.A.

$\begin{array}{ll}\text { Hoteles } & 0.26\end{array}$

Clubes deportivos N.A.

Otros gastos de recreación: circos, museos, etc. N.A.

Restaurantes, cantinas y similares N.A.

Almuerzos $\quad-0.08$

Cafeterías N.A.

Cantinas N.A.

Comunicaciones y servicios para vehículos

Teléfono particular $\quad 0.15$

Servicio telefónico local N.A.

Larga distancia nacional N.A.

Larga distancia internacional N.A.

Gasolina, diesel o gas $\quad 0.23$

Aceites y lubricantes $\quad-0.08$

Pensión y estacionamiento N.A.

Vivienda y servicios de conservación

Vivienda propia $\quad 0.51$

Mantenimiento y servicios de conservación N.A.

Vivienda rentada o alquilada N.A.

Energía eléctrica $\quad 0.08$

Gas doméstico $\quad 0.09$

Velas y veladoras N.A.

Otros combustibles: cartón, papel, etc. $\quad 0.04$

N.A.: No Aplica 


\begin{tabular}{ll}
\hline \hline & Factor \\
\hline \hline Prendas de vestir, calzado y accesorios & \\
Pantalones para hombre de mezclilla & \\
Pantalones para hombre de fibras sintéticas & 0.06 \\
Pantalones para mujer de mezclilla & 0.11 \\
Pantalones para mujer de fibras sintéticas & N.A. \\
Chamarras y chaquetas & -0.13 \\
Blusas y playeras para mujer & 0.12 \\
Trajes & -0.10 \\
Vestidos & N.A. \\
Conjuntos para mujer & N.A. \\
Faldas & N.A. \\
Abrigos & 0.13 \\
Suéteres & N.A. \\
Calzoncillos y truzas & 0.05 \\
Camisetas y playeras & 0.04 \\
Calcetines & N.A. \\
Calcetas y mallas & N.A. \\
Pantaletas & 0.07 \\
Medias, pantimedias y tobimedias & N.A. \\
Calzoncillos para niño & N.A. \\
Vestidos para niña & N.A. \\
Pantaletas para niña & 0.11 \\
Pijamas y batas & N.A. \\
Otras prendas para hombre (corbatas, etc.) & N.A. \\
Otras prendas de vestir & 0.08 \\
Pantalones de niño de fibras sintéticas & N.A. \\
Pantalones de niño de algodón & 0.07 \\
Blusas para niño & N.A. \\
Playeras para bebé & 0.04 \\
Suéter para niño & N.A. \\
Suéter para niña & N.A. \\
Uniformes escolares para niño & N.A. \\
Uniformes escolares para niña & N.A. \\
Zapatos para hombre & N.A. \\
Zapatos para mujer & N.A. \\
Zapatos para niño & 0.13 \\
Tenis & 0.10 \\
Otro tipo de calzado: huaraches, sandalias, etc. & 0.08 \\
Servicio de limpieza y reparación de calzado & N.A. \\
Sombreros, gorros y cachuchas & N.A. \\
Bolsas, portafolios y cinturones & N.A. \\
Joyería y joyería de fantasía & N.A. \\
Relojes & N.A. \\
\hline \hline N.A. No Aplica. & N.A. \\
\hline
\end{tabular}

N.A.: No Aplica 


\begin{tabular}{|c|c|}
\hline & Factor \\
\hline \multicolumn{2}{|l|}{ Cristalería, blancos y utensilios domésticos } \\
\hline Vajilla y piezas de cristal o barro & N.A. \\
\hline Artículos de plástico & 0.05 \\
\hline Baterías de cocina & N.A. \\
\hline Otros utensilios de cocina & N.A. \\
\hline Colchones & N.A. \\
\hline Cobertores y cobijas & N.A. \\
\hline Sábanas & N.A. \\
\hline Colchas & N.A. \\
\hline Toallas & -0.07 \\
\hline Cortinas & N.A. \\
\hline Hilos, hilazas y estambres & N.A. \\
\hline Otros blancos para el hogar & N.A. \\
\hline \multicolumn{2}{|l|}{ Cuidados de la Salud } \\
\hline Análisis médicos & N.A. \\
\hline Hospitalización & N.A. \\
\hline Ambulancia y material de cirugía & N.A. \\
\hline Anteojos y otros aparatos & N.A. \\
\hline \multicolumn{2}{|l|}{ Enseres domésticos y mantenimiento de la vivienda } \\
\hline Ventiladores & 0.05 \\
\hline Servicio doméstico & N.A. \\
\hline Máquinas de coser & -0.09 \\
\hline Estufas de gas & N.A. \\
\hline Refrigeradores & N.A. \\
\hline Licuadoras & -0.10 \\
\hline Plancha & N.A. \\
\hline Lavadoras & N.A. \\
\hline Calentadores de agua & 0.02 \\
\hline Otros enseres eléctricos & N.A. \\
\hline Juego de recámara & N.A. \\
\hline Juego de comedor o ante comedor & N.A. \\
\hline Piezas sueltas para comedor & N.A. \\
\hline Juego de sala & N.A. \\
\hline Muebles para cocina (gabinetes, etc.) & N.A. \\
\hline \multicolumn{2}{|l|}{ Artículos de esparcimiento } \\
\hline Radios y grabadoras & N.A. \\
\hline Estéreo y modular & N.A. \\
\hline Televisores y video caseteras & N.A. \\
\hline Equipo fotográfico & N.A. \\
\hline Juguetes & N.A. \\
\hline Instrumentos musicales & N.A. \\
\hline Artículos de deporte y cacería & -0.07 \\
\hline \multicolumn{2}{|l|}{ Transporte } \\
\hline Transporte ferroviario & N.A. \\
\hline Transporte aéreo & N.A. \\
\hline Cuotas de autopista & 0.08 \\
\hline Automóvil & N.A. \\
\hline Bicicletas & N.A. \\
\hline Llantas & N.A. \\
\hline Acumulador & N.A. \\
\hline Refacciones & N.A. \\
\hline Servicio de afinación, alineación y balanceo & N.A. \\
\hline
\end{tabular}

N.A.: No Aplica 


\section{Cuadro A3 (continuación)}

\begin{tabular}{lc}
\hline \hline & Factor \\
\hline \hline Otros gastos & \\
Funerales, cementerios & -0.05 \\
Impuesto sobre tenencia & N.A. \\
Seguro de automóvil & 0.61 \\
Trámites para vehículos: licencias, placas, etc. & -0.07 \\
& \\
\hline \hline N.A.: No Aplica
\end{tabular}

N.A.: No Aplica 